Research Article

\title{
Study on Steady-State Responses of High-Speed Vehicle Using Infinite Long Track Model
}

\author{
Wubin Cai (iD) and Maoru Chi \\ State Key Laboratory of Traction Power, Southwest Jiaotong University, Chengdu 610031, China \\ Correspondence should be addressed to Maoru Chi; cmr2000@163.com
}

Received 10 October 2019; Revised 2 February 2020; Accepted 17 February 2020; Published 26 March 2020

Academic Editor: Angelo Marcelo Tusset

Copyright (c) 2020 Wubin Cai and Maoru Chi. This is an open access article distributed under the Creative Commons Attribution License, which permits unrestricted use, distribution, and reproduction in any medium, provided the original work is properly cited.

\begin{abstract}
The coupled vehicle/track dynamic model is formulated through integrating a high-speed rail vehicle model with a slab track model via the wheel/rail contact model. The sliding window method is improved using the least square criterion to simulate the vehicle travelling along the infinite long track. The steady-state responses of a high-speed vehicle induced by the discrete sleepers and slab segments are investigated through numerical simulation and analysis of the experimental results. Also the validity of the coupled vehicle/track model is examined through comparing the simulation results with those acquired from field test measurements. The experimental and numerical results show that the wheel/rail contact forces fluctuate considerably as long as the sleeper passing frequency approaches the frequency of P2 resonance (wheelset and rail bouncing in phase on the slab). Increasing the damping of rail pads and primary suspension can lower the steadystate response amplitudes at the resonance region. The oscillations in the wheel/rail normal forces arising from the discrete slab segment excitation can be reduced by increasing the support stiffness of the CAM (cement asphalt mortar) layer under the slab.
\end{abstract}

\section{Introduction}

The steady-state response of a rail vehicle, caused by the excitation arising from the periodically discrete support under the rail such as sleepers and slabs, can lead to periodic oscillations in both the wheel/rail normal forces and the axle box accelerations. These periodic oscillations occur in the $0 \sim 200 \mathrm{~Hz}$ frequency range when a high-speed train operates in a speed range of $0 \sim 400 \mathrm{~km} / \mathrm{h}$. The resulting excitation at the wheel/rail interface can excite some vibration modes of the vehicle and track system and further contribute considerably to the wheel/rail interaction and in turn the noise emission [1]. Neglecting the steady-state response, the vehicle/track dynamic model could underestimate the wheel/rail forces. It is thus desirable to model the wheel/rail interaction more realistically to better understand the dynamic responses caused by either the sleepers or the slabs.
A number of vehicle/track excitation models have been developed to analyze the interaction between the vehicles and the tracks. Knothe and Grassie [2] gave an overview of the excitation models between the vehicle and track, such as the moving irregularity model and the moving mass model. The moving irregularity model has been widely employed to represent the vehicle/track excitation in the past decades. In the model, the vehicle is fixed on the middle position of the track analyzed, while the track irregularity moves backward with respect to the vehicle at the forward speed of the vehicle. This model is capable of predicting the dynamic responses induced by the track irregularities, while the excitation caused by the discrete support under the rail is neglected. The moving mass model represents the vehicle as a mass moving on the rails with respect to the track and track irregularities, which is commonly considered as a more realistic representation of the wheel/rail interaction and the excitation arising from the discrete support under the rails. 
Modelling a vehicle travelling on an infinite long track can be further generalized as a moving load acting on an infinite long beam supported on discrete supporters. In the early studies, a vast number of investigations have been performed to study the wave propagation on an infinite long beam supported on the continuous Winkler foundation or the discrete supporters [3-5], which contributed to modelling of a rail vehicle running on an infinite long track on discrete supporters. Using the Green function, Nordborg [1] represented the rail as a periodically supported infinite long beam subjected to a moving wheel and investigated the sleeper passing impact using the frequency-domain solution. $\mathrm{Wu}$ and Thompson [6] developed an equivalent timevarying track model coupled with a wheel using the spacevarying receptance to investigate the parametric excitation arising from the discrete sleepers. The study concluded that the proposed equivalent model overestimates the wheel/rail normal forces in the high frequency range, compared with those obtained via the moving irregularities model.

The aforementioned infinite long track models are invariably modelled in the frequency domain, and the representation of the track system is limited to the linear characteristics of the track system rather than the nonlinear characteristics. Modelling in time domain is usually more complicated and less efficient than frequency domain, but it could take into account the nonlinear factors, such as wheel/ rail contact relationship and wheel lift-off. With the improvement in computer performance, there has been a greater interest to study the coupled vehicle/track dynamics in time domain. High-performance computer made it possible to solve the numerical solution of the system dynamic equation by the numerical method of step-by-step integration efficiently. However, how to avoid the vehicle running distance exceeding the track length in time domain simulation became a common problem. And huge efforts thus have been made so far. Ripke and Knothe [7] represented the rail as a Timoshenko beam discretely supported on rigid sleepers through the rail pads, and the rigid sleepers are supported on the ballast. In order to reduce the reflection at both ends of the analyzed track, a $500 \mathrm{~m}$ long track is considered. The rail is modelled as a closed ring through connecting the two ends to form an imaginary circle. Dong et al. [8] used the "cutting and merging" method to present the track as an infinite long track, the track is modelled by the finite element method, and the vehicle is initially located in the centre position of the track to avoid the end effects. A short section at the rear end would be cut off every time when the vehicle passes over the distance equal to the cut away length, and meanwhile a new section is merged to the front end. By using this procedure, the vehicle can run on the track forever, while the size of system matrices does not increase. Alternatively, among the time domain models, many researchers [9-15] formulated rail as analytical vibration equations of beam with finite length and solved them using a modal superposition method. For these modelling approaches, several attempts have been made to extend the finite long rail into infinite. Baeza and Ouyang [13] proposed a "cyclic system" model to represent the infinite long track model, in which the rail is modelled as a cyclic Timoshenko beam using the modal approach. Xiao et al. [11] developed the "tracking window" method to simulate the train running on an infinite long track. In the tracking window, the vehicle is treated as stationary, while both of the irregularity and track support move in the reverse direction at the vehicle speed with respect to the stationary vehicle. Ling and Jin [12] extended the "tracking window" method to the case of multivehicles and the whole train. Zhang et al. [14] first proposed the concept of "sliding window" method to model the infinite long track. In the model, a finite long sliding window covering the effective area of the vehicle/track system moves forward with the moving vehicle, and the dynamic behaviours of the track within the sliding window are only taken into consideration. How to smooth the transition of window sliding is a difficult problem. In this paper, the sliding window method is well implemented using the least square criterion.

The steady-state response at the wheel/rail interface due to the periodical support can pose significant influences on the dynamic response of vehicle and track system with the deterioration of the track system. Dong [16] investigated a loaded wheel travelling on a discrete support track at a constant speed and concluded that the fluctuation of wheel/ rail normal forces due to the discrete support may exceed 5\% of the static load, and a softer rail pad may reduce the fluctuation in the wheel/rail contact forces arising from the sleeper impact. Nordborg [1] pointed out that the wheelballast resonance excited by the sleeper passing impact could yield higher fluctuation in the wheel/rail contact forces. Similar results were also observed by Wu et al. [17] through the numerical simulation using a finite element coupled vehicle/track dynamic model and the field test measurements acquired from a high-speed rail vehicle travelling on a slab track.

Using the instrumented wheelset, Gullers et al. [18] experimentally investigated the sleeper passing impact acquired on the Stockholm-Gothenburg railway line. They concluded that the track with stiff rail pads can yield a higher fluctuation in the wheel/rail normal forces, up to $\pm 15 \mathrm{kN}$, and the resilient rail pad could help reduce the steady-state response at the wheel/rail interface due to the discrete support. In addition to the slab segment-inducing the steady-state response, $\mathrm{Li}$ and $\mathrm{Wu}$ [19] suggested that the impact loads due to the discrete slab segments are highly dependent upon the length of slab and the vehicle speed through an investigation into a rail vehicle travelling on a floating slab track. Hussein and Hunt [20] stated that the fluctuation of wheel/rail contact forces caused by discontinuous slab segments is quite small when the velocity is less than $100 \mathrm{~km} / \mathrm{h}$, while the dynamic effect arising from the slab segment could be more important for high-speed or heavyhaul trains.

The sleeper passing impact has been regarded as one of the main noise resources, and its associated fluctuation in the wheel/rail interface could contribute to the formation of rail corrugation. Through experimental measurements, Färm [21] suggested that the sleeper passing impact-induced structure-borne sound could serve as the main resource of the noise in the coach. Using a coupled vehicle/track 
dynamic model, $\mathrm{Wu}[22,23]$ investigated the effects of parametric excitations on the wheel/rail rolling noise and the formation of rail corrugation. The results suggested that the wheel/rail noise caused by the sleeper passing impact at lower speeds is small and can be considered as negligible, while it cannot be neglected at high speeds. Moreover, the fluctuation of the wheel/rail contact forces due to the sleeper passing impact could also contribute considerably to the formation of rail corrugation. Szolc [24] suggested that the sleeper passing impact may excite some vibration modes of the vehicle and track system, further leading to the generation of the grumbling noise and the local plastic deformations on the running surfaces of wheel/rail. Jin et al. [25] pointed out that the wheel/rail lateral creepage induced by the sleeper passing impact likely serves as the main contributor to the formation of the rail corrugation on the tangent track.

The intensified wheel/rail interaction due to the steadystate responses can further contribute to the formation of defects on the wheel and rail and the noise emission. It is thus desirable to study the wheel/rail steady-state responses due to the discrete supporters and the slab segments in highspeed operation, which will facilitate the research development of track maintenance criterion. These also serve as the motivation of this investigation. In this study, the experimental results acquired from field tests are primarily used to characterize the steady-state responses induced by the discrete supporters and the slab segments. Moreover, a coupled vehicle/track dynamic model is modelled consisting of a high-speed rail vehicle travelling on an infinite long slab track, which is employed to study the influences of design and operating parameters of the vehicle and track system on the steady-state responses.

\section{Modelling of Vehicle and Track System}

The vehicle and track system is modelled through coupling a high-speed rail vehicle with a slab track via wheels/rails in the rolling contact model. In the model, the rail vehicle is formulated as a rigid multibody dynamic model. For the naturally infinite slab track system, a sliding window method is applied, as shown in Figure 1. This method can effectively predict the dynamic responses of the vehicle running on an infinite long track.

In this scheme, the dynamic behaviours of a track system in the length range $l$ of sliding window are considered representing the interested dynamic behaviours of the vehicle/track system with reasonable accuracy and efficiency. The vehicle is initially located at the left side of the sliding window and always moves in the range of sliding window. Here, in such a window, the track is treated as a piece-wise finite structure for which a mathematical solution based on the modal approach has been used. After the running distance approaches $L_{m}$ (equals to a multiple of a slab length), the vehicle reaches the right side of the sliding window regarded as the end position. Then, the window (window 1) moves forward the distance $L_{m}$ to a new position (window 2 ), which is regarded as a completed iterative step. This procedure leads to the identical initial relative location

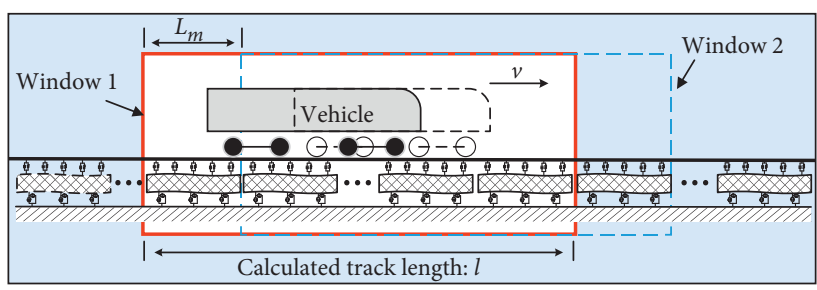

FIgURE 1: A simulation scheme of the vehicle travelling on an infinite long track.

between the vehicle and the sliding window for each iterative step, while it gives rise to different initial states of the track system for each iterative step. The initial state of the track in the current iterative step has to be identical to the end state of the track system obtained in the previous iterative step. The dynamic responses of the vehicle over a relatively long running distance can thus be determined by repeating this procedure.

2.1. Vehicle Model. The vehicle model is a typical highspeed rail vehicle consisting of a carbody supported on two bogies through the secondary suspensions. Each bogie includes two wheelsets and a bogie frame, and each wheelset is coupled to the bogie frame through the vertical damper and coil spring as well as the axle box along the longitudinal direction. In the model, the primary and secondary suspensions are modelled as parallel combinations of equivalent linear springs and viscous dampers in the three translational directions. The carbody, the bogie frames, and wheelsets are modelled as rigid bodies with 6 degrees-of-freedom (DOF), while each axle box is only permitted to pitch with respect to the wheelset to which it is attached, as shown in Figure 2.

The vehicle model is further coupled with the slab track model through using the wheel/rail contact model. In the wheel/rail contact model, the tangent force at the wheel/rail interface is determined by using the FASTSIM algorithm [26], while the normal force is calculated by using the Hertzian theory [27], representing the wheel/rail normal force as a function of the penetration between the wheel and rail profiles, such that

$$
F_{n}(t)= \begin{cases}{\left[\frac{1}{G_{H}} \delta Z(t)\right]^{3 / 2},} & \delta Z(t)>0, \\ 0, & \delta Z(t) \leq 0,\end{cases}
$$

where $G_{H}$ is the Hertz contact constant $\left(\mathrm{m} / \mathrm{N}^{3 / 2}\right)$ and $\delta Z(t)$ is the penetration between the wheel and rail profile.

2.2. Finite Long Slab Track Model. In a sliding window, the finite long track model consists of two rails discretely supported on the track slab segments through the fasteners and rail pads, and the slab segments are further continuously supported on the roadbed through the cement asphalt mortar (CAM) layer, as shown in Figure 3. 


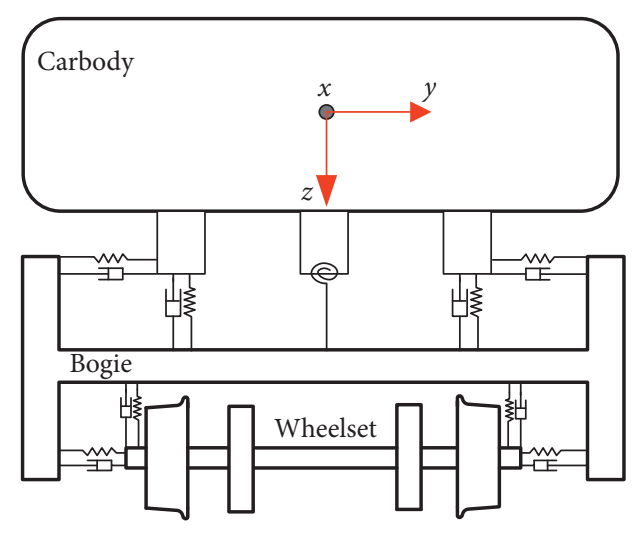

(a)

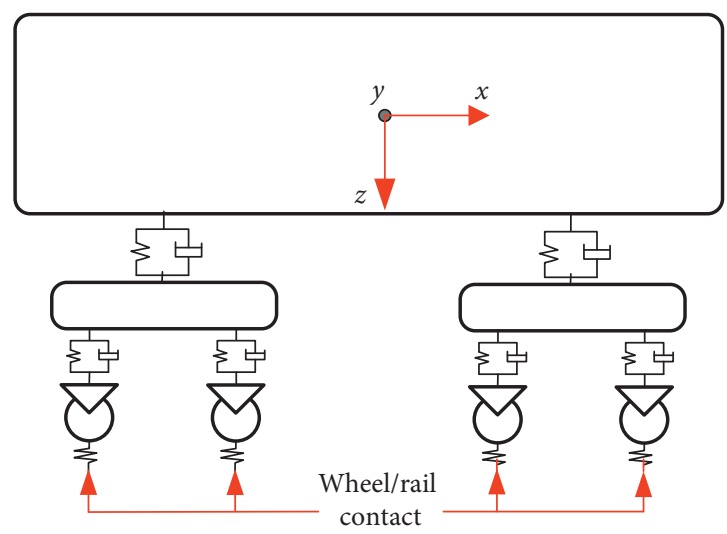

(b)

Figure 2: A schematic of vehicle dynamic model.

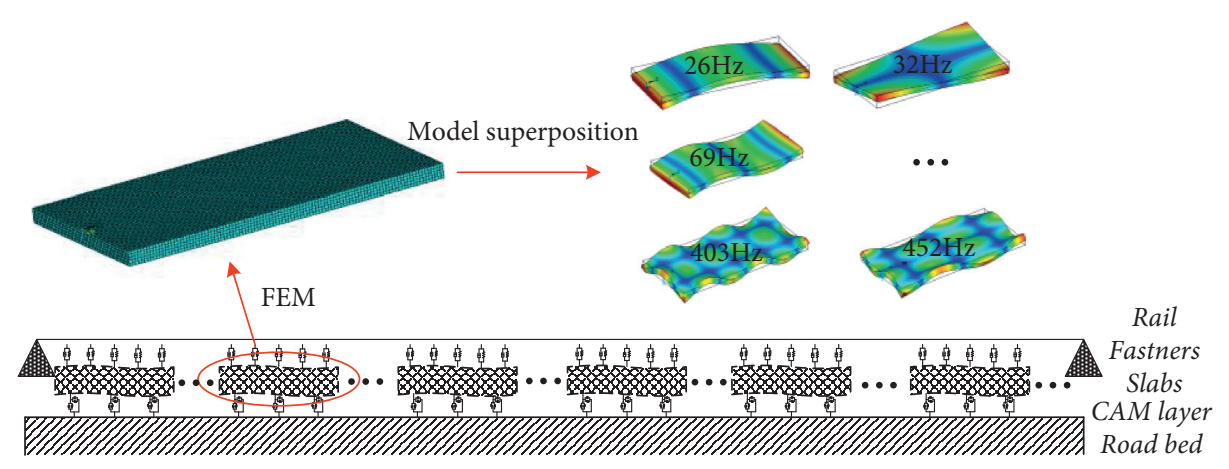

FIGURE 3: Slab track system used in the high-speed railway line.

The rail is formulated as Timoshenko beam hinged at both ends. Although we consider the vibration of the rail in three directions, the vertical deformation of the rail is the most important when studying the steady-state responses. Therefore, the vertical deflection of the rail is discussed in detail here, and the equations of lateral and torsional deflection can refer to $[9,14,28]$.

According to the Timoshenko beam theory, the rail vertical deflection $z$ responses subjected to the moving wheel/rail contact forces $F_{w r z j}$ owing to the $j$ th wheel and the support forces $F_{s z i}$ due to the $i$ th rail pad acting between the rail and slab can thus be given by

$$
\begin{array}{r}
\rho A \frac{\partial^{2} z(x, t)}{\partial t^{2}}+\kappa_{z} G A\left[\frac{\partial \psi_{z}(x, t)}{\partial x}-\frac{\partial^{2} z(x, t)}{\partial x^{2}}\right] \\
=-\sum_{i=1}^{N_{s}} F_{s z i} \delta\left(x-x_{s i}\right)+\sum_{j=1}^{N_{w}} F_{w r z j} \delta\left(x-x_{w j}\right), \\
E I_{y} \frac{\partial^{2} \psi_{z}(x, t)}{\partial t^{2}}+\kappa_{z} G A\left[\psi_{z}(x, t)-\frac{\partial z(x, t)}{\partial x}\right] \\
-E I_{y} \frac{\partial^{2} \psi_{z}(x, t)}{\partial x^{2}}=0,
\end{array}
$$

where $\psi_{z}$ is the slope of deflection curve of rail with respect to vertical axes. $E$ and $G$ denote Young's modulus and the shear modulus of rail material. The rail density and area of rail's cross section is presented by $\rho$ and $A$. $I_{y}$ is the crosssectional bending moment about rail's lateral axes. $\mathcal{K}_{z}$ indicates the vertical shear coefficient. $\delta(x)$ is the Dirac delta function. The locations of the $i$ th fastener and $j$ th wheel are determined by $x_{s i}$ and $x_{w j}$. The total numbers of fasteners and wheels under consideration are $N_{s}$ and $N_{w}$. Using the modal superposition method, the deflection responses described in the above governing partial differential equations can be transformed to a set of ordinary equations in terms of generalized coordinates $q_{z k}(t)$ and $w_{z k}(t)$, such that

$$
\begin{gathered}
z(x, t)=\sum_{k=1}^{N_{V}} Z_{k}(x) q_{z k}(t), \\
\psi_{z}(x, t)=\sum_{k=1}^{N_{V}} \Psi_{z k}(x) w_{z k}(t),
\end{gathered}
$$

where $N_{V}$ is the total number of vibration modes under consideration. $Z_{k}(x)$ and $\Psi_{z k}(x)$ are the mode shape functions of the rail. Substituting equations (4)-(5) into equations (2)-(3), the partial differential equations can be 
transformed to a set of second-order ordinary equations, such

$$
\begin{gathered}
\ddot{q}_{z k}(t)+\frac{\kappa_{z} G A}{\rho A}\left(\frac{k \pi}{l}\right)^{2} q_{z k}(t)-\kappa_{z} G A \frac{k \pi}{l} \sqrt{\frac{1}{\rho^{2} A I_{y}}} \omega_{z k}(t) \\
=-\sum_{i=1}^{N_{s}} F_{s z i} Z_{k}\left(x_{s i}\right)+\sum_{j=1}^{N_{w}} F_{w r z j} Z_{k}\left(x_{w j}\right) \\
\ddot{\omega}_{z k}(t)+\left[\frac{\kappa_{z} G A}{\rho I_{y}}+\frac{E I_{\mathrm{y}}}{\rho I_{y}}\left(\frac{k \pi}{l}\right)^{2}\right] \omega_{z k}(t) \\
-\kappa_{z} G A \frac{k \pi}{l} \sqrt{\frac{1}{\rho^{2} A I_{y}}} q_{z k}(t)=0
\end{gathered}
$$

The wheel/rail contact force can also be transmitted to the slab through the rail and rail pads, therefore leading to the bending deformation in the slab. The lateral deflection of the slab, however, is considered negligible compared to the bending deflection of the slab. The vertical deflection in the slab segments is thus only considered using the modal approach subjected to the discrete rail pads' forces $\mathbf{F}_{i}^{r}$ and the support forces $\mathbf{F}_{i}^{\mathcal{g}}$ arising from the CAM layer:

$$
\begin{aligned}
\ddot{X}_{n i}+2 \zeta_{n} \omega_{n} \dot{X}_{n i}+\omega_{n}^{2} X_{n i}=\Pi_{n}^{T} \mathbf{F}_{i}^{r}+\Pi_{n}^{T} \mathbf{F}_{i}^{g}, \\
n=1 \sim N_{\text {mode }}, i=1 \sim N_{\text {slab }},
\end{aligned}
$$

where $X_{n i}$ is the generalized coordinate for the $n$th mode in the $i$ th slab. $\omega_{n}$ and $\zeta_{n}$ are the circular frequency and damping ratio of the $n$th mode. $\Pi_{n}$ is the $n$th modal shape vector. In this study, the modal matrix of slab is determined by the modal analysis in the ANSYS platform. The finite element model of slab is formulated using the hexahedron solid 45 element with the total number of 26,000 nodes. A total number of 30 vibration modes (including 6 rigid modes) are considered with the maximum frequency occurring at $450 \mathrm{~Hz}$.

\subsection{Simulation Scheme of a Vehicle Travelling on an Infinite} Long Track. The dynamic responses of a rail vehicle running over a relatively long distance are always of great interest, and a number of methods thus have been proposed to model the infinite long track in the past decades $[7,8,11,13,14]$. The concept of the sliding window method is first proposed by Zhang and Song [14, 29]; however, the way to eliminate the artificial disturbances at the instant of sliding window may lead to an unstable solution. In this study, we give a better adaptable method to eliminate the artificial disturbances when sliding the window, which make the transition between the two sliding windows smoother.

For better understanding, the transient states of the vehicle/track system are illustrated using different plots, as shown in Figure 4. Because the method is unrelated with the vehicle, the vehicle is thus simplified as a moving wheel with an equivalent load. The dynamics of the track system in the range $l$ of the sliding window are considered, representing the interested dynamic behaviours of the vehicle/track system. The vehicle is initially located at the centre region of the track in sliding window 1 (SW1) to avoid the end effects (the dashed-line wheel). After the vehicle travels the distance of $L_{m}$ along the track (the solid-line wheel), the SW 1 moves forward for distance $L_{m}$, which turns out the sliding window 2 (SW2). It is expected that this procedure would introduce some artificial disturbances on the track. Thus, the initial dynamic states in the interested track section in SW2, including displacements, velocities, accelerations, and forces responses, should be as close as possible to the states of the track at the end of SW1 to eliminate the effects of artificial disturbances. The overlap region of SW 1 and SW2 is taken as specified track range, which indicates that the initial states of track range $0 \sim 1-L_{m}$ in SW2 must be identical to the end states of track range $L_{m} \sim l$ in SW1. The initial states in the outside of the specified track range $L_{m} \sim l$ for SW2 are temporarily taken as zero.

As the vehicle is located in SW2, the responses of the rails, slab segments, and force elements in SW2 in the initial position can thus be determined by using these responses obtained from the end position states in SW1; for example,

$$
\begin{gathered}
F_{\text {rp_win2 }}\left(0<x<l-L_{m}\right)=F_{\text {rp_win1 }}\left(L_{m}<x<l\right), \\
F_{\text {ca_win2 }}\left(0<x<l-L_{m}\right)=F_{\text {ca_win1 }}\left(L_{m}<x<l\right), \\
Z_{\text {slab_win2 }}\left(0<x<l-L_{m}\right)=Z_{\text {slab_win1 }}\left(L_{m}<x<l\right), \\
Z_{\text {rail_win2 }}\left(0<x<l-L_{m}\right)=Z_{\text {rail_win1 }}\left(L_{m}<x<l\right),
\end{gathered}
$$

where $l$ is the length of the sliding window, $L_{m}$ is the forward distance of the vehicle in each iteration, and both of them should be multiples of a slab length. $F_{\text {rp_win2 }}$ and $F_{\text {rp_win1 }}$ represent the force responses of the rail pads in SW2 in the initial position and SW1 in the end position, respectively. $F_{\text {ca_win2 }}$ and $F_{\text {ca_win1 } 1}$ represent the force responses of the CAM layer at the corresponding two positions, $Z_{\text {slab win2 }}$ and $Z_{\text {slab_win } 1}$ denote the dynamic responses of the slab, and $Z_{\text {rail_initial }}$ and $Z_{\text {rail_end }}$ are the dynamic responses of the rail.

In this sliding window, the rail is modelled as a continuous Timoshenko beam using the modal approach. The dynamic responses of rail in SW2 in the initial position can also be given by

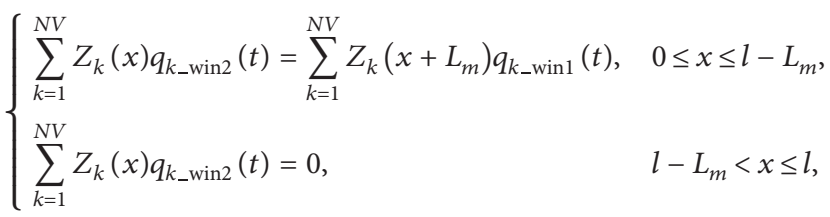

where $q_{k_{-} \text {win2 }}(t)$ and $q_{k_{-} \text {win } 1}(t)$ are the generalized coordinates of the rail in SW2 and SW1, respectively. The modal shape function $Z_{k}(x)$ of the rail is time-independent variable, while the generalized coordinates $q_{k_{- \text {win2 } 2}}(t)$ and $q_{k_{-} \text {win } 1}(t)$ are the time-dependent variables. In order to determine the generalized coordinates $q_{k_{-} \text {win2 }}(t)$ in SW2 in the initial position, the sliding window is discretized into $M$ segments along the track direction, indicated by the longitudinal coordinates $x_{1}, x_{2}, x_{3}, \ldots x_{m}$. The generalized 


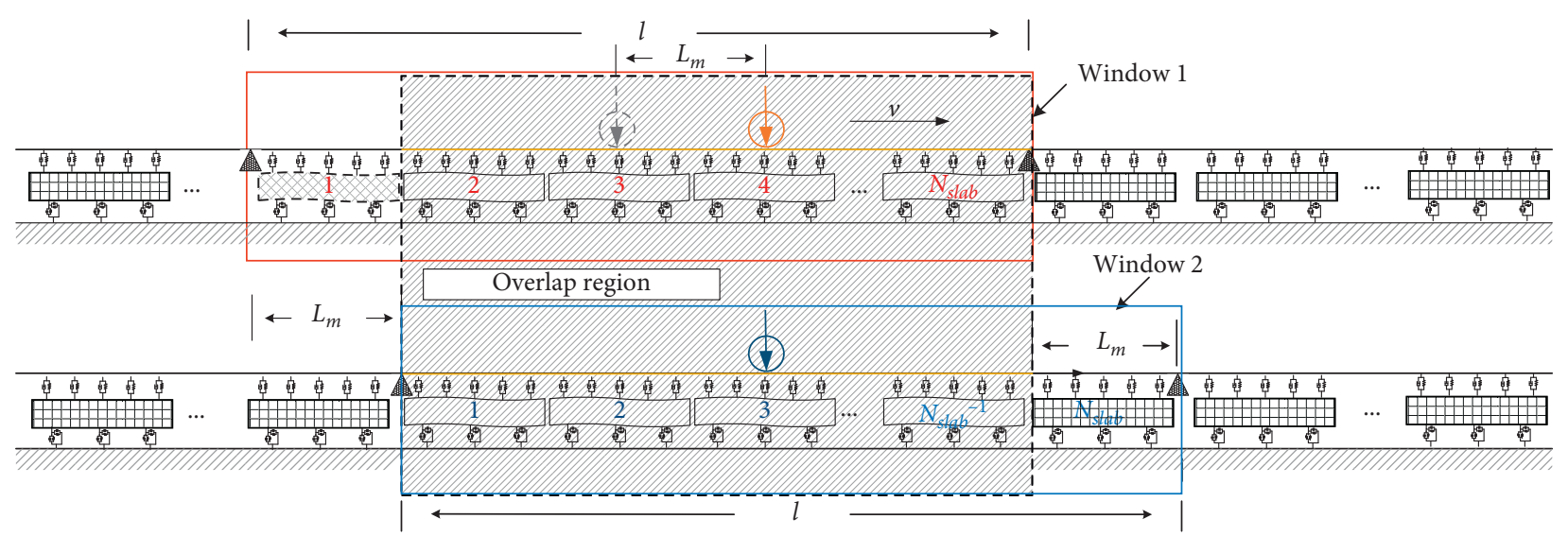

Figure 4: Transient states of the vehicle/track systems.

coordinates for the initial position $\mathbf{Q}$ thus can be determined through solving a set of linear algebraic equations, which read

$$
\Phi_{v} \mathbf{Q}=\mathbf{D}
$$

where $\boldsymbol{\Phi}_{v}$ is the $M \times N_{V}$ normalized modal matrix, $\mathbf{Q}$ is the generalized coordinates of the initial position state in SW2 with the dimension of $N_{V} \times 1$, and $\mathbf{D}$ is the deformation vector of $M$ discrete points along the track obtained in SW1 at the end position.

It is noted that the dynamic responses at the rear end (form $l-L_{m}$ to $l$ ) of SW2 are manually set to zero at the window-sliding instant. In other words, there is an inevitable sudden change from nonzero to zero in the $l-L_{m}$ position of SW2. Under these circumstances, when we take $M$ equal to $N_{V}$, there is naturally a unique solution for the equation set (10). However, the coefficient matrix $\mathbf{Q}$ is near singular due to this sudden change, which will lead to an unstable solution. Figure 5(a) gives an example to demonstrate such instability, in which we choose a sliding window covering $65.416 \mathrm{~m}$ track containing 13 slabs, and each slab has 8 fasteners with $0.629 \mathrm{~m}$ spacing, the forward distance $L_{m}=5.032 \mathrm{~m}$, which equals to a slab length. For simplification, only vertical vibration is considered, and the rail's modal number $N_{V}$ is set to 200 . When $M$ is 200 and the matrix's triangular decomposition is adopted to find the numerical solution of equation (10), the states of the rail at the sliding instant are plotted in Figure 5(a).It is seen that the initial states of the rail in SW2 diverge at the rear end of the window. In order to overcome this divergence problem, it is recommended taking the number of discrete points $M$ greater than the number of considered vibration modes $N_{V}$. Then, the linear equation set (10) turns to an overdetermined system. The least square criterion is thus introduced to calculate the generalized coordinates of the rail for the initial position states and reads as follows [30]:

$$
\min _{\mathbf{Q} \in R^{N_{V}}}\left\|\Phi_{\nu} \mathbf{Q}-\mathbf{D}\right\| \text {. }
$$

Figure 5(b) presents the rail acceleration in the case of $M$ equals to 250 , equation (10) is solved with the least square criterion. The initial state of the rail in SW2 is much closer to the end state in window 1 , which makes the window sliding smoother. With a $2.9 \mathrm{GHz}$ processor, the total computing time for the vehicle passing through the $L_{m}$ length is $1.072 \mathrm{~s}$. And among the total time, the computing time for the windowsliding procedure is $0.0225 \mathrm{~s}$, whose proportion is only $2.1 \%$. In other words, the sliding window method with least square criterion is efficient enough and could meet calculation time requirements of vehicle/track coupling dynamics.

Therefore, through implementation of this iterative scheme together with the vehicle and track model, a vehicle running on an infinite long track can be simulated irrespective of the operating distances.

2.4. Model Validation and Comparison. The sliding window method is validated through comparing the wheel/rail forces with those obtained using the moving mass model and the moving irregularity model [2], considering two scenarios. Figure 6 illustrates the wheel/rail normal forces owing to the vehicle passing over a rail joint at $300 \mathrm{~km} / \mathrm{h}$, calculated by the moving mass model and the sliding window method, respectively. The rail joint is represented by using a combination of the two cosine irregularities with different wavelengths $\left(\lambda_{1}=1.0 \mathrm{~m}\right.$ and $\left.\lambda_{1}=0.1 \mathrm{~m}\right)$, as shown in Figure 6(a). The amplitudes for the long- and short-wave irregularities are that $\delta_{1}=0.3 \mathrm{~mm}$ and $\delta_{1}=0.3 \mathrm{~mm}$, respectively. And the rail joint is intentionally applied at the instant when sliding the window. As shown in Figure 6(b), the wheel/rail contact forces calculated using the two models are very close in the amplitude and the fluctuation trend in the impact region. There are typical P1 force and P2 force [31] when the wheel passes the rail joint. The peak value calculated by the moving mass model is $191.55 \mathrm{kN}$ and $191.52 \mathrm{kN}$ by the "sliding window" method, and the difference is only $0.01 \%$ between them. However, after running $17 \mathrm{~m}$, the wheel/rail forces diverge from the steady state in the moving mass model because the vehicle reaches the end of the track. However, the sliding window method could simulate the vehicle running on an infinite long track.

The proposed infinite long track model is further validated through simulation of the vehicle passing by a tangent track with the stochastic irregularity at $300 \mathrm{~km} / \mathrm{h}$. The 


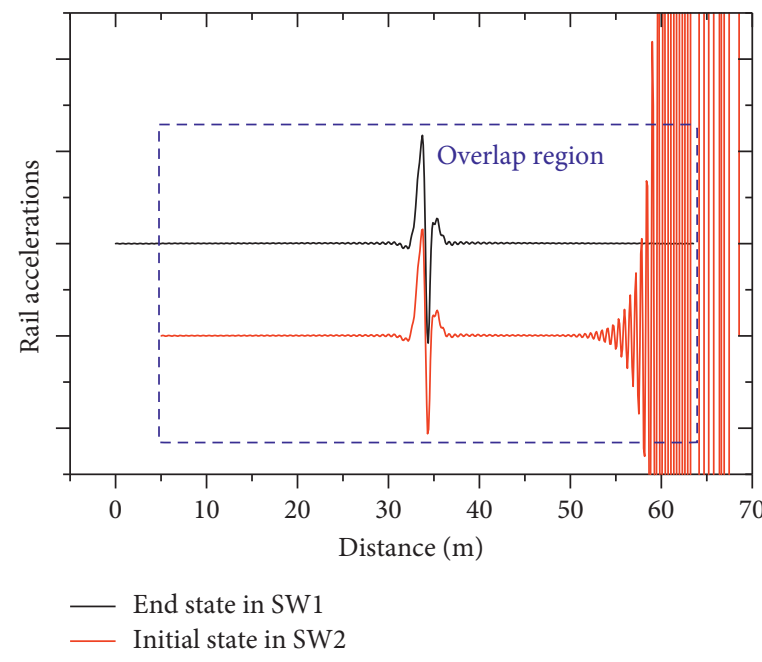

(a)

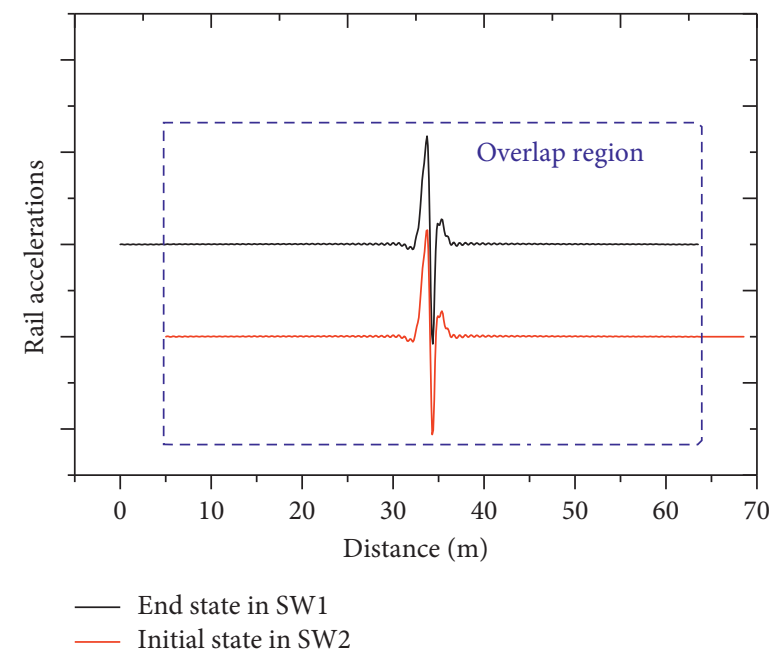

(b)

Figure 5: Transient states of the rail at the sliding moment when using (a) matrix's triangular decomposition and (b) the least square criterion.

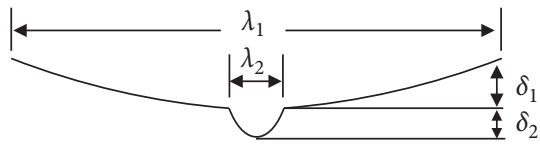

(a)

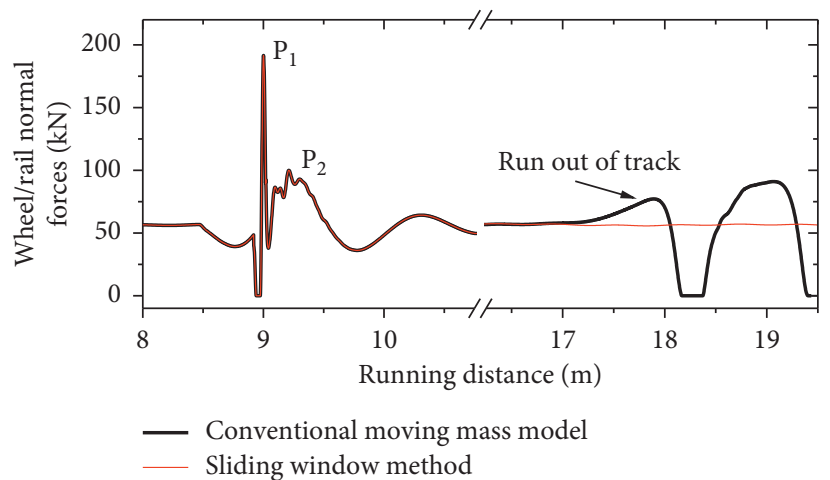

(b)

FIGURE 6: The vehicle passing over a rail joint irregularity: (a) rail joint irregularity model; (b) wheel/rail normal force variations owing to the rail joint irregularity excitation.

obtained wheel/rail contact forces are compared with those obtained via the moving irregularities model. Some small differences can be identified in the time history (Figure $7(\mathrm{a})$ ) of wheel/rail normal forces and from the spectra (Figure 7(b)). These differences are believed owing to the sleeper passing effect. Therefore, the proposed method is more realistic, comparing to the moving irregularity model.

In summary, Table 1 lists the advantages and drawbacks of these three models. The moving mass model is the most realistic one, which could reflect the periodic impact owing to the track discrete support. But it could not implement the long-distance simulation. On the contrast, in the moving irregularity model, the vehicle stays on the track and will never reach the end of track. However, the moving irregularity model ignores the parametric excitations. Combining the advantages of both, the sliding window method is capable of simulating a vehicle running on an infinite long track subjected to the periodic impact. Furthermore, the proposed method is proved both efficient and accurate according to the above numerical simulation.

\section{Results and Discussion}

The experimental results obtained from two different field tests are used to characterize the steady-state responses. The steady-state responses induced by the discrete sleeper support are illustrated with the experimental data obtained from a high-speed train running on the Ha'erbinDalian (HD) high-speed railway line. The steady-state responses to the slab segment excitation are measured from the Zhengzhou-Xuzhou (ZX) high-speed railway line. The experimental data acquired in different seasons are compared in the frequency domain to illustrate the influences of the temperature change on the steady-state responses of the rail vehicle. Using the proposed coupled vehicle and track dynamic model, the main factors influencing the steady-state response are investigated 


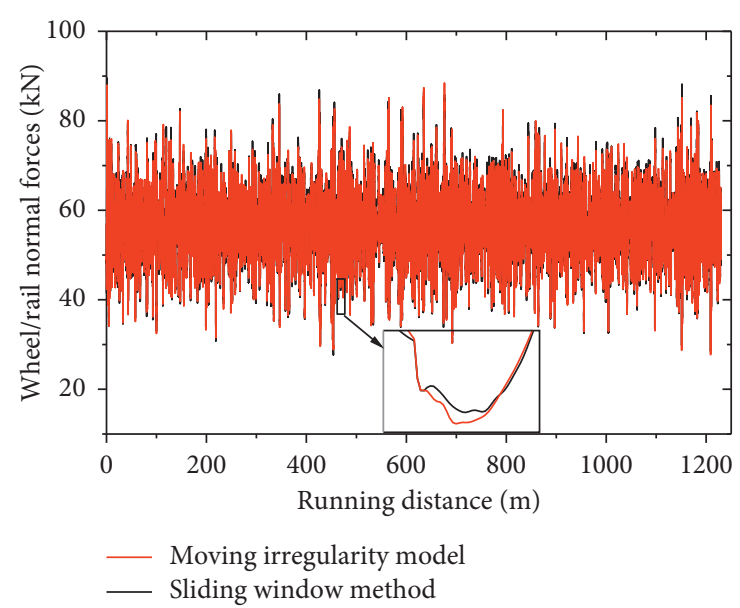

(a)

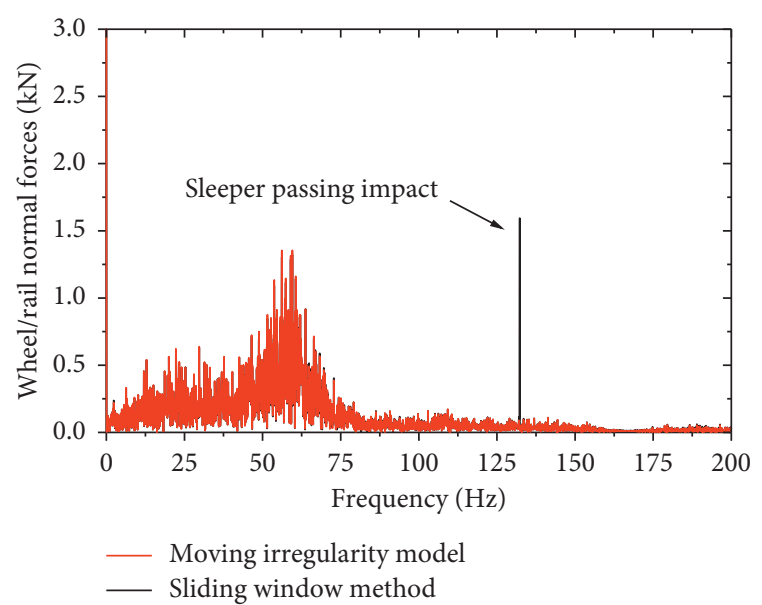

(b)

FIgURE 7: Comparison of wheel/rail normal forces between the proposed model and the moving irregularity model: (a) time domain; (b) frequency domain.

TABle 1: Comparison of three models.

\begin{tabular}{lccc}
\hline & Moving mass model & Moving irregularity model & Sliding window method \\
\hline Long-distance simulation & $\times$ & $\checkmark$ & $\checkmark$ \\
Reflect periodic impact owing to the track discrete support & $\checkmark$ & $\times$ & $\checkmark$ \\
Computational cost & Low & Low & Low \\
\hline
\end{tabular}

considering different parameters. Table 2 illustrates important parameters used in the vehicle/track dynamic model.

\subsection{Steady-State Responses owing to Discrete Sleeper Supports}

3.1.1. Sleeper Passing Impacts in the Experimental Measurements. Figure 8(a) illustrates the vertical acceleration responses of the axle box, bogie frame, and car body obtained from a high-speed train running on HD high-speed railway line. The vehicle speed is $200 \mathrm{~km} / \mathrm{h}$. The vertical accelerations of the axle box and the bogie frame show the obvious sinusoid fluctuations at $88 \mathrm{~Hz}$. This frequency corresponds to the passing frequency of sleepers as a vehicle passes over the sleepers with $0.629 \mathrm{~m}$ bay between the adjacent two sleepers at $200 \mathrm{~km} / \mathrm{h}$, as shown in Figure 8(b). The vertical acceleration responses of the car body in the frequency domain also show the sleeper passing frequency although the sleeper passing impact is not evident in the time domain. Owing to the sleeper passing impact at the wheel/ rail interface, the vertical acceleration of the axle box reaches about $4 \mathrm{~g}$, which can excite some vibration modes of the vehicle/track system up to the frequency $130 \mathrm{~Hz}$ in the speed range of $0 \sim 300 \mathrm{~km} / \mathrm{h}$.

The sleeper impact loads are highly dependent on the support stiffness of track system [17], especially the stiffness characteristic of rail pads. Since the rail pad is made of rubber, its stiffness property varies with the ambient temperature, which can further lead to considerable variation between the summer and the winter. The measurements shown in Figures 9(a) and 9(b) illustrate the frequency spectra of the axle box accelerations obtained in the winter and the summer. In the initial stage of operation of $\mathrm{HD}$ railway line, the vehicle speed is limited to $200 \mathrm{~km} / \mathrm{h}$ in the winter, while the vehicle operates at $300 \mathrm{~km} / \mathrm{h}$ in the summer. It can be seen that the amplitudes at the sleeper passing frequency $(88 \mathrm{~Hz})$ in the winter are much larger than those obtained in the summer at the sleeper passing frequency $(132 \mathrm{~Hz})$, which could be attributed to the considerable change in the support stiffness of the track system between the summer and the winter. Wei et al. [32] proved that the stiffness of rail pad in a low temperature can increase to $130 \mathrm{MN} / \mathrm{m}$ from a nominal stiffness $40 \mathrm{MN} / \mathrm{m}$.

3.1.2. Parametric Study. By using the proposed vehicle/ track dynamic model, the influences of the parameters of the vehicle/track on the sleeper passing impact are discussed. Figure 10 illustrates the maximum accelerations of the axle box caused by the sleeper passing impact considering different vehicle speeds and rail pad stiffness. The critical speed, at which the resulting axle box acceleration increases substantially, is identified in the vehicle speed range of $80 \sim 400 \mathrm{~km} / \mathrm{h}$. The axle box acceleration shows that the increase rate decreases with further increase in vehicle speed. In addition, this critical speed and associated axle box acceleration increase with the rail pad stiffness. It is thus believed that, at this critical speed, the sleeper passing frequency approaches the P2 resonance frequency of the system, and the coupled resonance 
TABLE 2: Value of parameters.

\begin{tabular}{|c|c|c|}
\hline Notation & Parameters & Value \\
\hline \multicolumn{3}{|l|}{ Track subsystem } \\
\hline$E\left(\mathrm{~N} / \mathrm{m}^{2}\right)$ & Young's modulus of rail & $2.059 \times 10^{11}$ \\
\hline$G\left(\mathrm{~N} / \mathrm{m}^{2}\right)$ & Shear modulus of rail & $7.9 \times 10^{10}$ \\
\hline$\rho\left(\mathrm{kg} / \mathrm{m}^{3}\right)$ & Density of rail & 7860 \\
\hline$A\left(\mathrm{~m}^{2}\right)$ & Cross-sectional area & $7.745 \times 10^{-3}$ \\
\hline$I_{y}\left(\mathrm{~m}^{4}\right)$ & Bending moment about $y$-axis & $3.217 \times 10^{-5}$ \\
\hline$\kappa_{z}$ & Vertical shear coefficient & 0.5329 \\
\hline$\rho_{s}\left(\mathrm{~kg} / \mathrm{m}^{3}\right)$ & Density of slab & 2800 \\
\hline$E_{s}\left(\mathrm{~N} / \mathrm{m}^{2}\right)$ & Young's modulus of slab & $3.6 \times 10^{10}$ \\
\hline$L_{s} \times D_{s} \times H_{s}(\mathrm{~m})$ & Dimension of slab & $4.962 \times 2.5 \times 0.17($ HD line $), 5.6 \times 2.5 \times 0.2(\mathrm{ZX}$ line $)$ \\
\hline$K_{\mathrm{pv}}(\mathrm{MN} / \mathrm{m})$ & Rail pad vertical stiffness & 40 \\
\hline$C_{\mathrm{pv}}(\mathrm{kN} \cdot \mathrm{s} / \mathrm{m})$ & Rail pad vertical damping & 52 \\
\hline$K_{\mathrm{sv}}(\mathrm{MN} / \mathrm{m})$ & Slab support vertical stiffness & 5000 \\
\hline$C_{\mathrm{sv}}(\mathrm{kN} \cdot \mathrm{s} / \mathrm{m})$ & Slab support vertical damping & 300 \\
\hline$l_{0}(\mathrm{~m})$ & Sleeper bay & 0.629 (HD line), 0.63 (ZX line) \\
\hline \multicolumn{3}{|l|}{ Vehicle subsystem } \\
\hline$M_{c}(\mathrm{~kg})$ & Carbody mass & 44039 \\
\hline$M_{t}(\mathrm{~kg})$ & Bogie mass & 2439 \\
\hline$M_{w s}(\mathrm{~kg})$ & Wheelset mass & 1881 \\
\hline$I_{t y}\left(\mathrm{~kg} \cdot \mathrm{m}^{2}\right)$ & Bogie pitch moment of inertia & 1846 \\
\hline$K_{s z}(\mathrm{MN} / \mathrm{m})$ & Vertical stiffness of secondary suspension & 0.24 \\
\hline$C_{s z}(\mathrm{kN} \cdot \mathrm{s} / \mathrm{m})$ & Vertical damping of secondary suspension & 25 \\
\hline$K_{p z}(\mathrm{MN} / \mathrm{m})$ & Vertical stiffness of primary suspension & 9 \\
\hline$C_{p z}(\mathrm{kN} \cdot \mathrm{s} / \mathrm{m})$ & Vertical damping of primary suspension & 10.5 \\
\hline$R_{w}(\mathrm{~m})$ & Wheel radius & 0.46 \\
\hline$L_{c}(\mathrm{~m})$ & Half distance between two bogie frames & 8.9 \\
\hline$L_{t}(\mathrm{~m})$ & Half of the bogie wheelbase & 1.25 \\
\hline
\end{tabular}

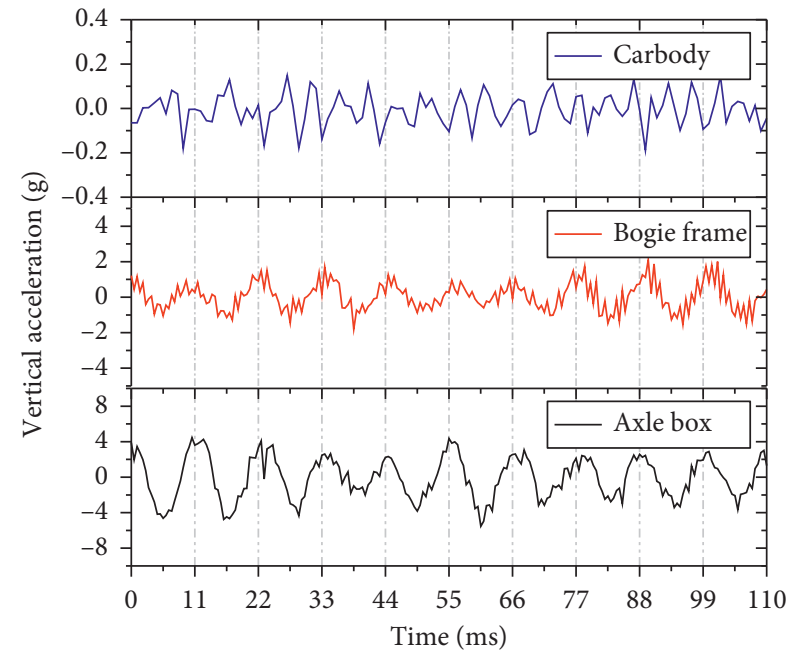

(a)

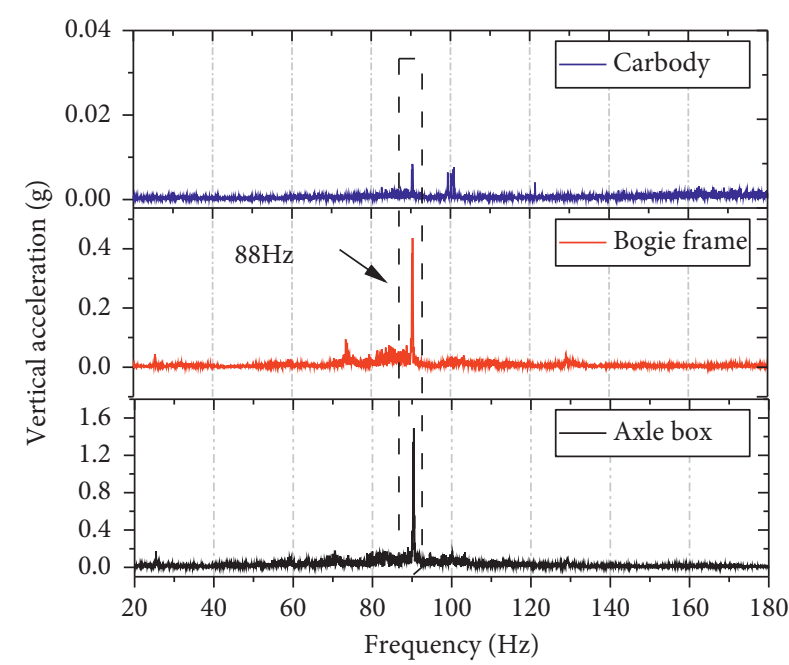

(b)

Figure 8: Sleeper passing impacts in test measurements: (a) time history of vertical accelerations of the vehicle components; (b) vertical accelerations in frequency domain.

occurs. Here, the P2 resonance [33-39] generally refers to the coupled system mode where wheelset, rails, and sleepers vibrate in phase on the subground for the ballast track. As for the slab track, the modal shape of P2 resonance is the wheelset and rail bouncing in phase on the slab, as shown in Figure 10.

The frequency of the $\mathrm{P} 2$ resonance could be simply written as [8] 


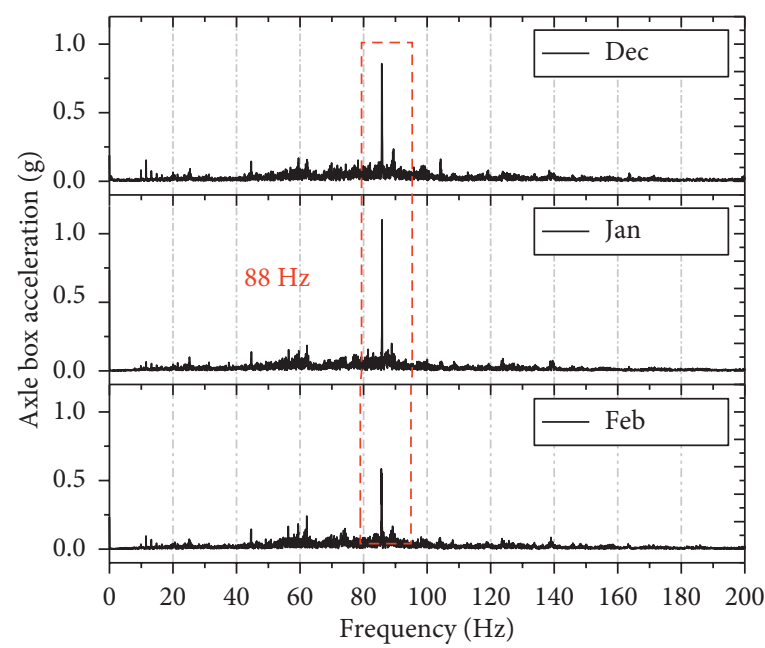

(a)

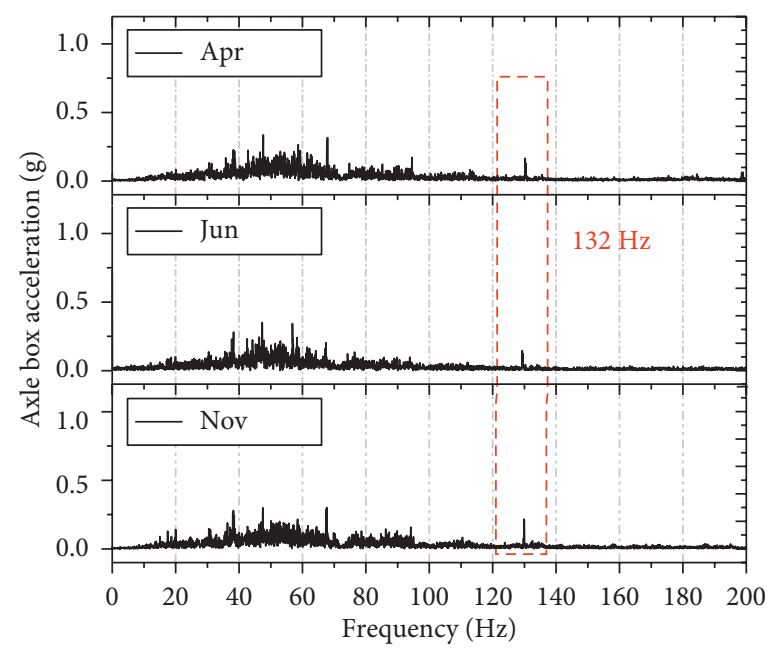

(b)

Figure 9: Comparison of frequency spectra of axle box accelerations obtained in different seasons: (a) the winter season (200 km/h); (b) the summer season $(300 \mathrm{~km} / \mathrm{h})$.

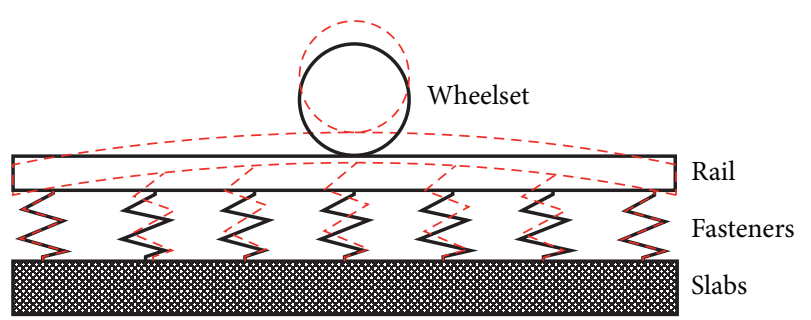

Figure 10: Diagram of the modal shape of P2 resonance.

$$
f_{p 2}=\frac{\sqrt{K_{\mathrm{Tr}} / M_{\mathrm{Tr}}+M_{w}}}{2 \pi}
$$

in which $M_{\mathrm{Tr}}$ and $M_{w}$ are half of the equivalent mass of track and wheelset and $M_{\mathrm{Tr}}$ denotes half of the equivalent track stiffness. They can be further expressed as

$$
\begin{aligned}
K_{\mathrm{Tr}} & =2 \times\left(4 \times E I_{z} \times k_{f}^{3}\right)^{0.25}, \\
k_{f} & =\frac{k_{\mathrm{pv}}}{l_{0}}, \\
M_{\mathrm{Tr}} & =3 \times m_{\mathrm{tr}} \times\left(\frac{E I_{z}}{K_{\mathrm{Tr}}}\right)^{1 / 3}=3 \times \rho A \times\left(\frac{E I_{z}}{K_{\mathrm{Tr}}}\right)^{1 / 3},
\end{aligned}
$$

where $E I_{z}$ is the bending stiffness of rail, $k_{f}$ is the equivalent support stiffness under the rail per unit length, and $m_{\mathrm{tr}}=\rho A$ is the track mass per unit length. Substituting equations (13)-(15) into equation (12), the P2 resonance frequency is given by

$$
f_{p 2}=\sqrt{\frac{2 \times\left(4 \times E I_{z} \times\left(k_{\mathrm{pv}} \% / l_{0}\right)^{3}\right)^{0.25} \% / 3 \times \rho A \times\left(E I_{z} \% /\left(4 \times E I_{z} \times\left(k_{p v} \% / l_{0}\right)^{3}\right)^{0.25} \% / 2\right)^{1 / 3}+\left(M_{w s} \% / q\right)}{2 \pi}} .
$$

When the rail pad stiffness $K_{\mathrm{pv}}$ increases from $40 \mathrm{MN} / \mathrm{m}$ to $140 \mathrm{MN} / \mathrm{m}$, other parameters take the nominal values in Table 2. The $\mathrm{P} 2$ resonance frequency $f_{p 2}$ calculated by the analytical formula increases from $51.4 \mathrm{~Hz}$ to $83.1 \mathrm{~Hz}$. After calculation, the resonance speeds should be $116.4 \mathrm{~km} / \mathrm{h}\left(3.6 \times f \times l_{0}=3.6 \times 51.4 \times 0.629\right)$ and $188.2 \mathrm{~km} /$ h $(3.6 \times 83.1 \times 0.629)$, respectively, which shows good agreement with the results in Figure 11. Furthermore, the resulting axle box acceleration (Figure 11) can reach about $2 \mathrm{~g}$ when the stiffness is $140 \mathrm{MN} / \mathrm{m}$, which is much larger than that considering the nominal rail pad stiffness.
Figure 12 illustrates the comparison of the axle box accelerations between the numerical results (pad stiffness $140 \mathrm{MN} / \mathrm{m}$ ) and the experimental results obtained in the winter. The comparison shows a good agreement between them. Both the results show the identical dominant frequency of $88 \mathrm{~Hz}(200 / 3.6 / 0.629)$ and the amplitudes in both time and frequency domains at $200 \mathrm{~km} / \mathrm{h}$. In the winter, the lowest ambient temperature of $\mathrm{HD}$ railway line is about $-40^{\circ} \mathrm{C}$, which could substantially increase the support stiffness of the track system. The one thus can deduce that the increased stiffness of rail pads in the winter could serve as 


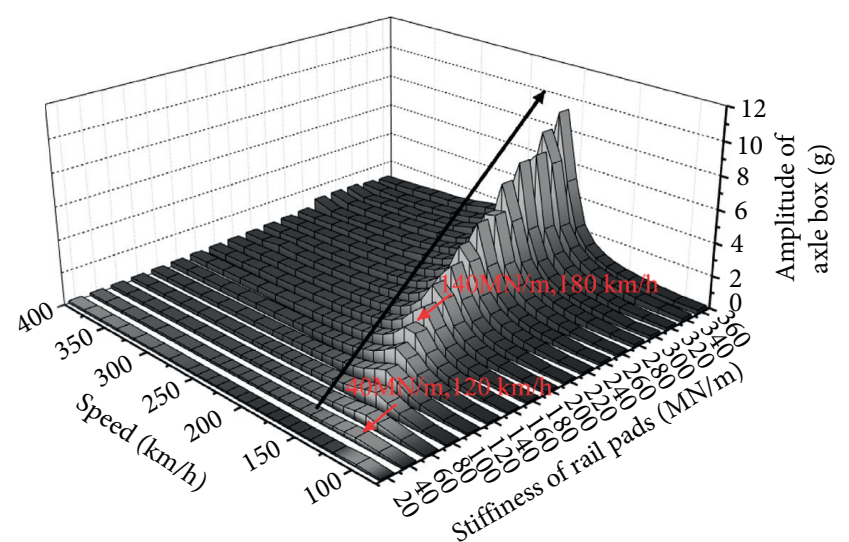

FIGURE 11: Maximum axle box accelerations due to sleeper passing impacts considering different vehicle speeds and vertical stiffness of rail pad.
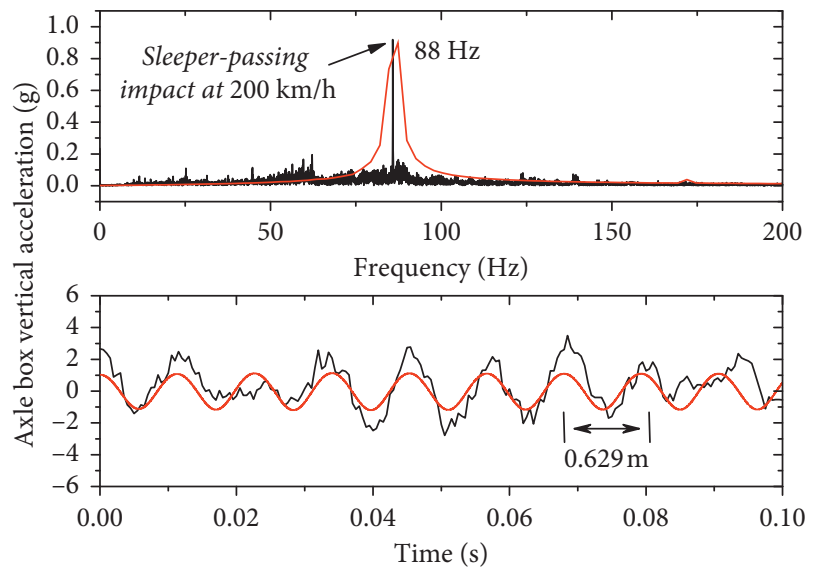

— Field test

- Simulation

Figure 12: Comparison of the axle box vertical accelerations between the simulation results and the field test measurements that were obtained in winter $\left(V=200 \mathrm{~km} / \mathrm{h}\right.$ and $\left.K_{\mathrm{pv}}=140 \mathrm{MN} / \mathrm{m}\right)$.

the main cause of the considerable sleeper passing impacts on HD high-speed railway line.

Figure 13(a) illustrates the influences of the vehicle speeds on the maximum and minimum wheel/rail normal forces with the rail pad stiffness of $200 \mathrm{MN} / \mathrm{m}$ and damping of $10 \mathrm{kN} \cdot \mathrm{s} / \mathrm{m}$. Owing to the sleeper passing impact exciting the $\mathrm{P} 2$ resonance, the wheel/rail interaction is subjected to considerable loading and unloading phenomenon at $180 \mathrm{~km} / \mathrm{h}$. These considerable fluctuations further lead to the impact force peak of $160 \mathrm{kN}$, and the wheel/rail separation occurs. The time histories of the wheel/rail normal forces vs. the vehicle travel distance are plotted in Figure 13(b) at $180 \mathrm{~km} / \mathrm{h}$, considering different rail pad damping $\left(C_{\mathrm{pv}}=10 \mathrm{kN} \cdot \mathrm{s} / \mathrm{m}\right.$ and $\left.52 \mathrm{kN} \cdot \mathrm{s} / \mathrm{m}\right)$. For the rail pad damping $C_{\mathrm{pv}}=10 \mathrm{kN} \cdot \mathrm{s} / \mathrm{m}$, the wheel $/$ rail separation occurs at the travelling distance of $0.629 \mathrm{~m}$, which is a sleeper bay. Nevertheless, the wheel regains the contact with the rail and the wheel/rail normal forces show the sinusoidal waveform with the increased rail pad damping $C_{\mathrm{pv}}=52 \mathrm{kN} \cdot \mathrm{s} / \mathrm{m}$, which suggests that a rational rail pad damping can effectively attenuate the fluctuation in the wheel/rail normal force when the $\mathrm{P} 2$ resonance occurs. This is also evident in the axle box acceleration responses, considering different rail pad damping, as shown in Figure 13(c). At the resonance region, the rail pad damping can lower the amplitude of the acceleration, while the effect of the rail pad damping is considered negligible in the other frequency region. It should be pointed out that the rail pad damping changing from $10 \mathrm{kN} \cdot \mathrm{s} / \mathrm{m}$ to $90 \mathrm{kN} \cdot \mathrm{s} / \mathrm{m}$ is not the real value in field, and this range is taken from the perspective of simulation purposes. The same is true for the following parametric studies.

The unsprung mass is also considered as one of the important parameters affecting the dynamic behaviour considering the sleeper passing impact. Figure 14 illustrates the effects of the unsprung mass considering the sleeper passing impact via increasing the unsprung mass from $0.5 t$ to $2.5 t$. The dynamic factor is defined as the ratio of dynamic deviations of the wheel/rail normal forces with respect to the static wheel load. It can be seen that the unsprung mass poses significant influences on the wheel/rail dynamic factor and the axle box acceleration. The increasing unsprung mass increases the wheel/rail force and however decreases the P2 resonance frequency and the amplitude in the axle box acceleration owing to the larger inertia.

Figure 15 further shows the effects of sleeper bay, axle load, and vertical damping of primary suspension on the axle box acceleration. It can be seen from Figure 15(a) that the longer sleeper bay causes the higher amplitude of the axle box acceleration. Moreover, one interesting finding is that the resonance speed grows with the sleeper bays, while the corresponding frequency (speed/bay) decreases slightly. As can be seen from Table 3, the resonance frequency is approximately $85.9 \mathrm{~Hz}$ when sleeper bay is $0.55 \mathrm{~m}$, and it decreases to $77.8 \mathrm{~Hz}$ when the sleeper bay is $0.75 \mathrm{~m}$. This is because the longer sleeper bay lowers the equivalent support stiffness of the track and then reduces P2 resonance frequency.

The axle load and the vertical damping of the primary suspension mainly affect the amplitude of the axle box acceleration. Although the axle load does not change the P2 resonance frequency, the larger axle load gives rise to the higher amplitude of the axle box acceleration in the whole speed range. The effects of the vertical damping of the primary suspension are just limited to the amplitude in the resonance region, which is similar to the rail pad damping.

\subsection{Steady-State Responses owing to the Slab Segment}

3.2.1. Slab Segment-Induced Impact Found by Experiments. The slabs are widely employed to construct high-speed railway lines so as to maintain the track irregularities are in a relatively small level. In the track systems, the discrete distributed slab segments are continuously supported on the CAM layer and coupled to the rail through the fastener system. Similar to the discrete sleeper support, the discrete distributed slab segments can also alter the support stiffness along the track and lead to the additional wheel/rail 


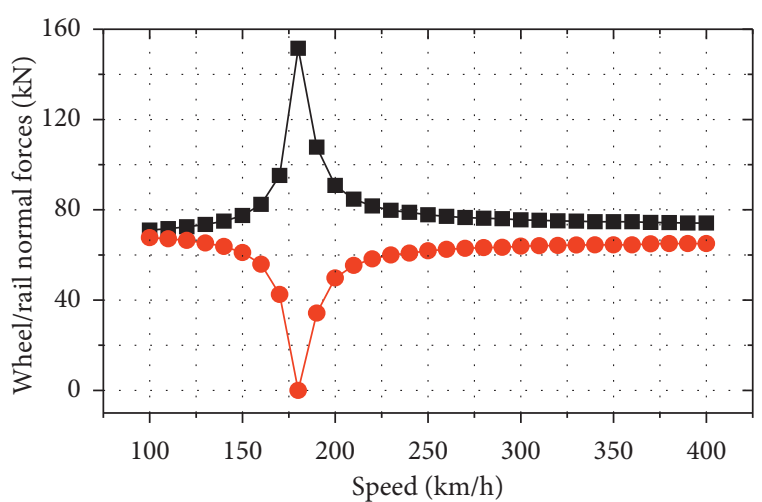

Maximun forces

Minimun forces

(a)

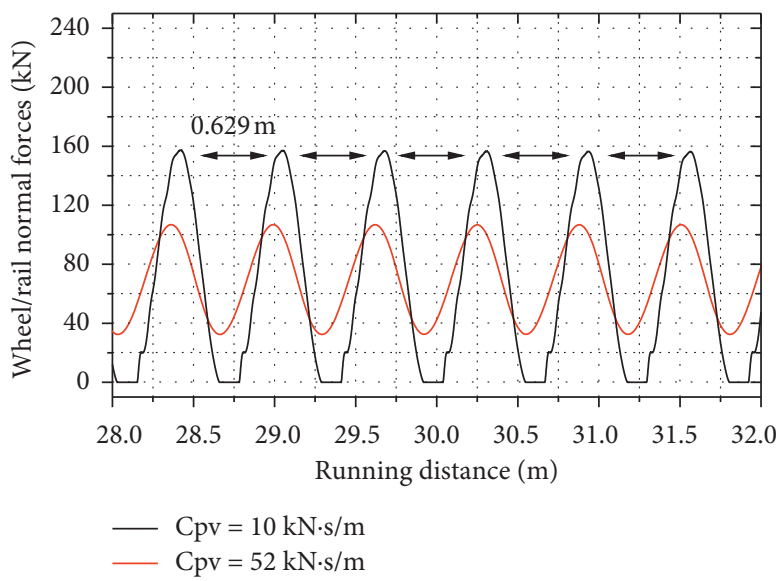

(b)

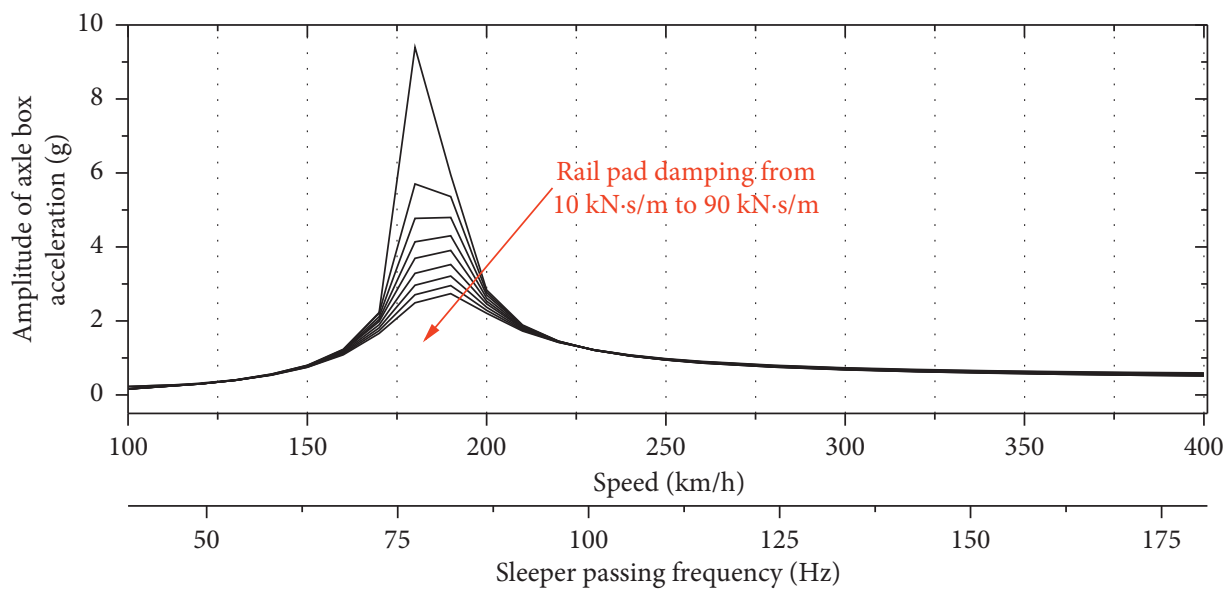

(c)

FIGURE 13: Wheel/rail normal forces and axle box accelerations due to sleeper passing impacts: (a) maxima and minima of wheel/rail normal forces obtained at different vehicle speeds $\left(K_{\mathrm{pv}}=200 \mathrm{MN} / \mathrm{m}\right.$ and $\left.C_{\mathrm{pv}}=10 \mathrm{kN} \mathrm{s} / \mathrm{m}\right) ;(\mathrm{b})$ comparison of the wheel/rail normal forces for rail pad damping $52 \mathrm{kN} \mathrm{s} / \mathrm{m}$ and $10 \mathrm{kN} \mathrm{s} / \mathrm{m}$; (c) effects of rail pad damping on the axle box accelerations.

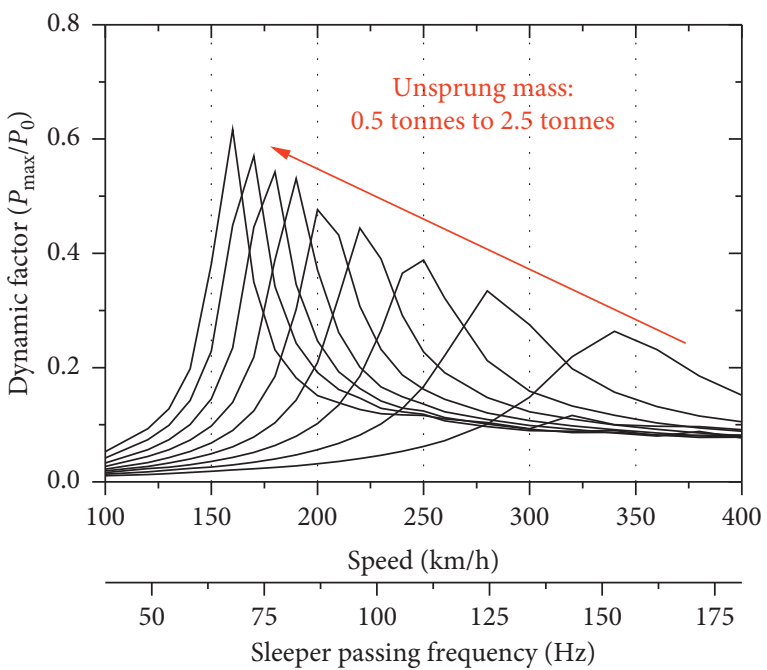

(a)

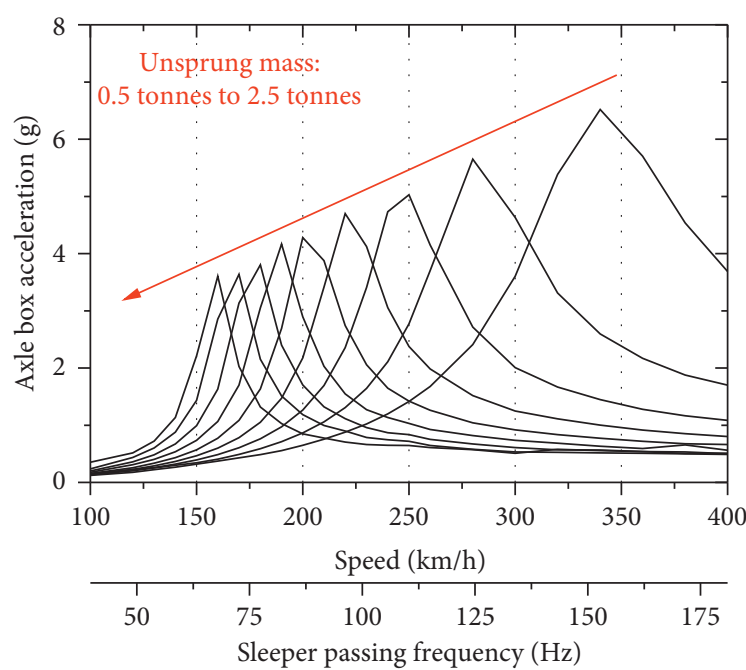

(b)

FIGURE 14: Effects of the unsprung mass on the sleeper passing impact: (a) dynamic factors; (b) axle box accelerations. 


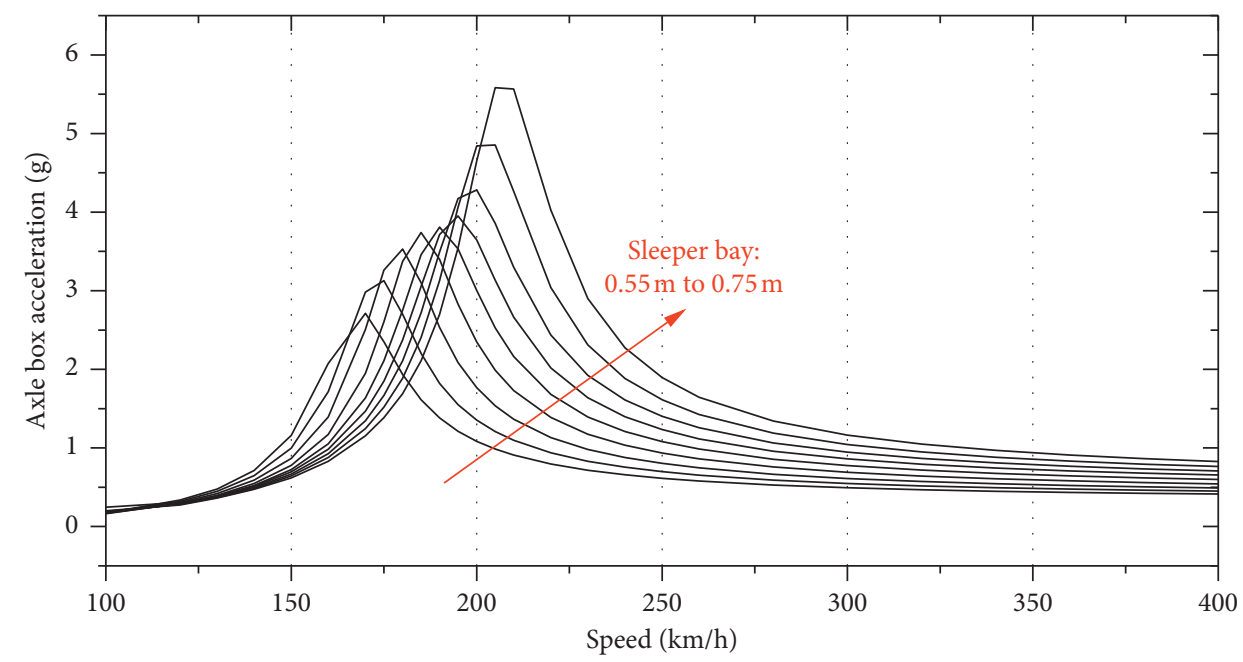

(a)

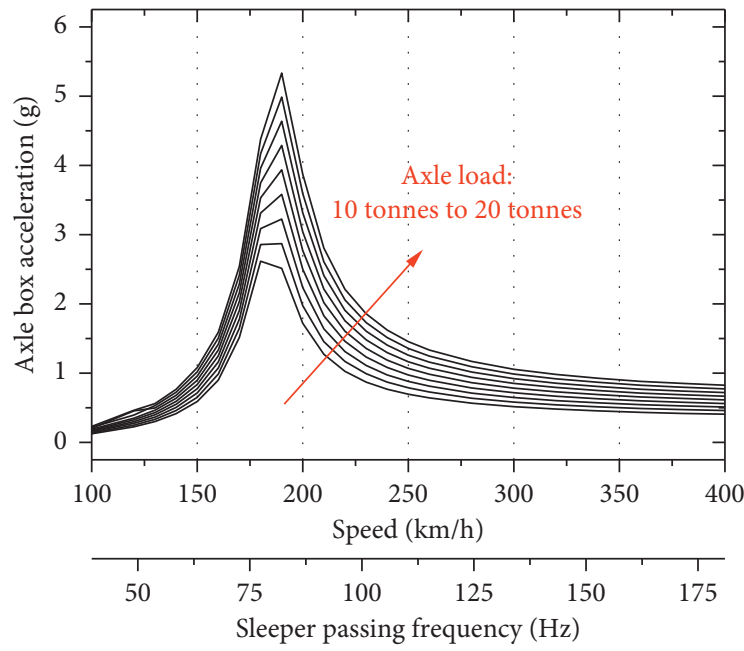

(b)

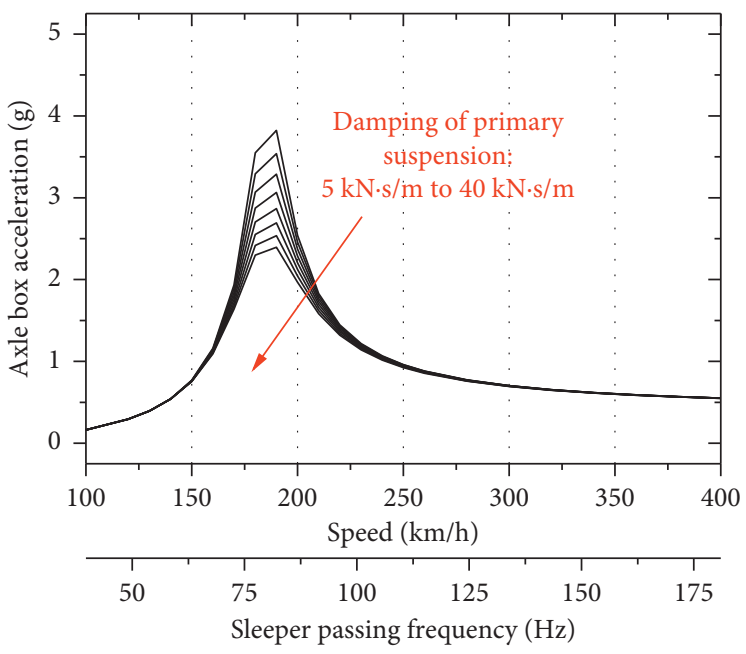

(c)

FIGURE 15: Axle box acceleration considering different parameters: (a) sleeper bay; (b) axle load; (c) vertical damping of primary suspension.

TABLE 3: Resonance speeds and frequencies under different sleeper bays.

\begin{tabular}{lccccccccc}
\hline Sleeper bay $(\mathrm{m})$ & 0.55 & 0.575 & 0.6 & 0.625 & 0.65 & 0.675 & 0.7 & 0.725 & 0.75 \\
Resonance speed $(\mathrm{km} / \mathrm{h})$ & 170 & 175 & 180 & 185 & 190 & 195 & 200 & 205 & 210 \\
Resonance frequency $(\mathrm{Hz})$ & 85.9 & 84.5 & 83.3 & 82.2 & 81.2 & 80.2 & 79.4 & 78.5 & 77.8 \\
\hline
\end{tabular}

impacting loads at the transition areas between two slab segments. Figure 16(a) and Figure 16(b)show the vertical displacement of the primary suspension measured from a high-speed train running between Zhengzhou and Xuzhou at $350 \mathrm{~km} / \mathrm{h}$. In the spectrum, the colour is used to quantify the amplitude of the vertical displacement of the primary suspension in the frequency domain. A speeddependent dominant frequency is identified in the frequency domain, and this dominant frequency is $17 \mathrm{~Hz}$ when the train operates at $350 \mathrm{~km} / \mathrm{h}$. The vibration of this frequency is caused by $5.6 \mathrm{~m}$ slab segment excitation.

The slab track irregularities are, in general, relatively small in the initial stage. It is expected that the slab segmentinduced impact can increase owing to the deterioration in the CAM layer. The slab segment-induced impact is investigated via the numerical simulation using the proposed vehicle/track dynamic model considering different CAM layer support stiffnesses.

3.2.2. Effects of Support Stiffness of Slab Segment on the Impact Loads. Figure 17 illustrates the steady-state responses in the wheel/rail normal forces and the axle box accelerations owing to the discrete sleeper support and the slab segment with different CAM lay support stiffnesses, $300 \mathrm{MN} / \mathrm{m}$ and $3000 \mathrm{MN} / \mathrm{m}$. Apart from the fluctuations with a wavelength of $0.63 \mathrm{~m}$, that is a sleeper bay, the wheel/rail normal force also oscillates with the wavelength 


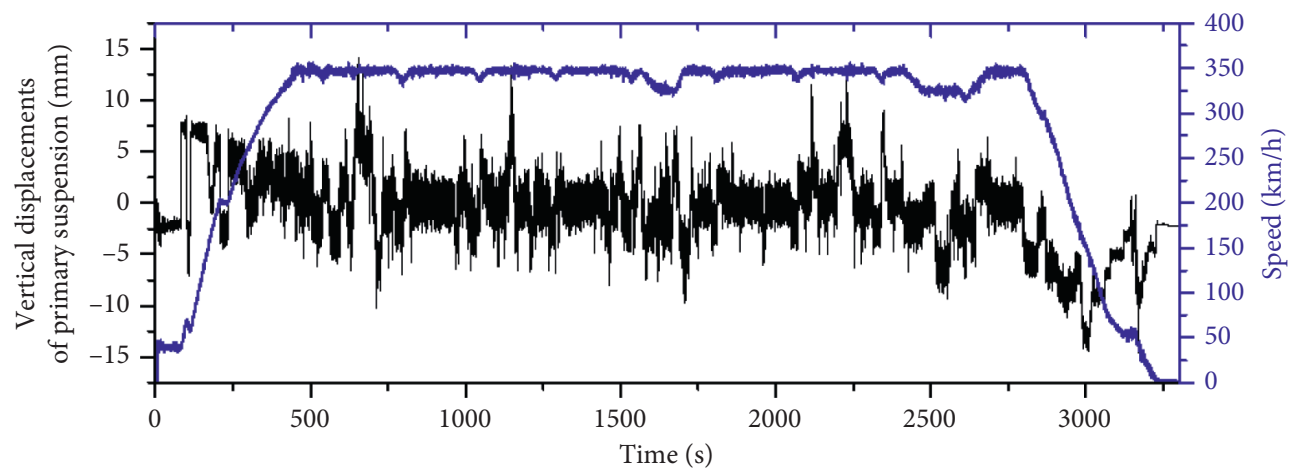

(a)

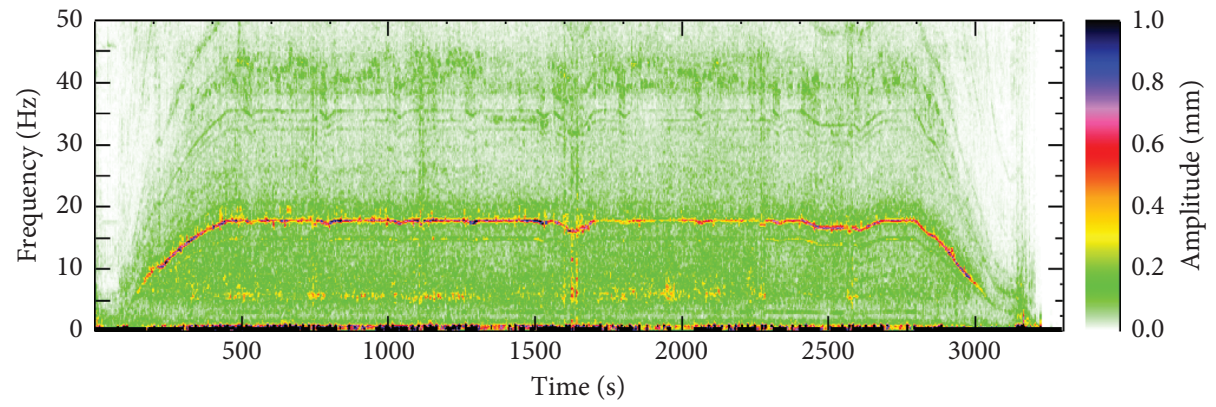

(b)

FIGURE 16: Slab segment-induced responses in the displacement of the primary suspension: (a) time history of the vertical displacement of the primary suspension and vehicle speed profile; (b) short-time Fourier transform of vertical displacements of the primary suspension obtained on a high-speed train running on the ZX high-speed railway line.

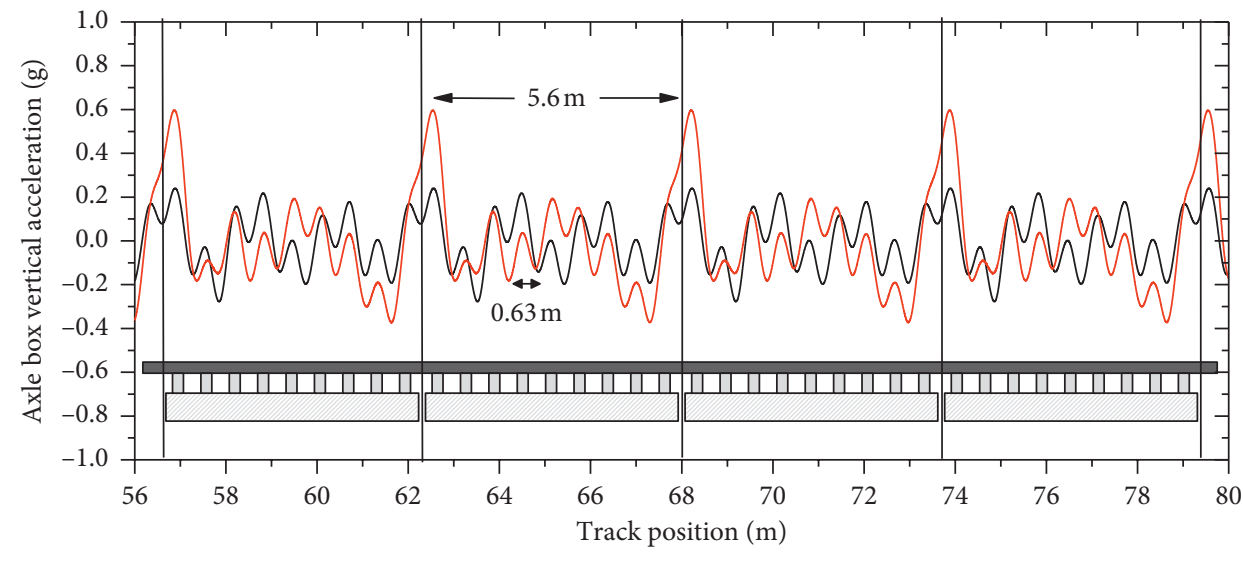

$\begin{aligned}-K_{\mathrm{sv}} & =3000 \mathrm{MN} / \mathrm{m} \\ -K_{\mathrm{sV}} & =300 \mathrm{MN} / \mathrm{m}\end{aligned}$

(a)

Figure 17: Continued. 


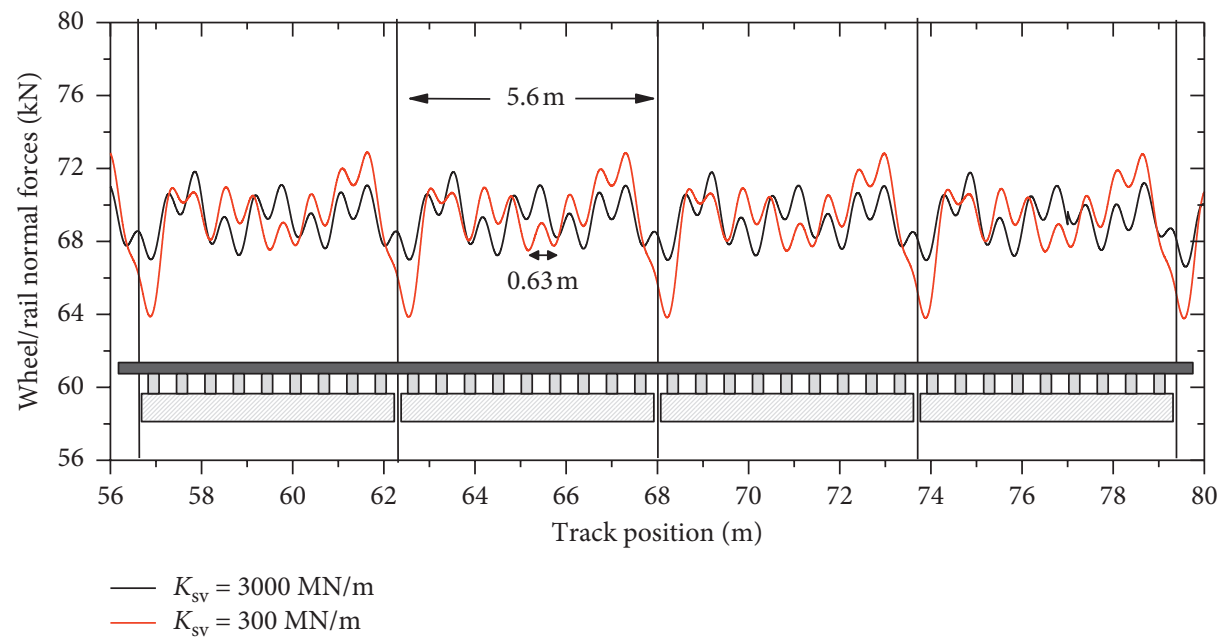

(b)

FIGURE 17: Dynamic responses due to discrete sleeper support and the slab segment: (a) axle box vertical acceleration; (b) wheel/rail normal forces.

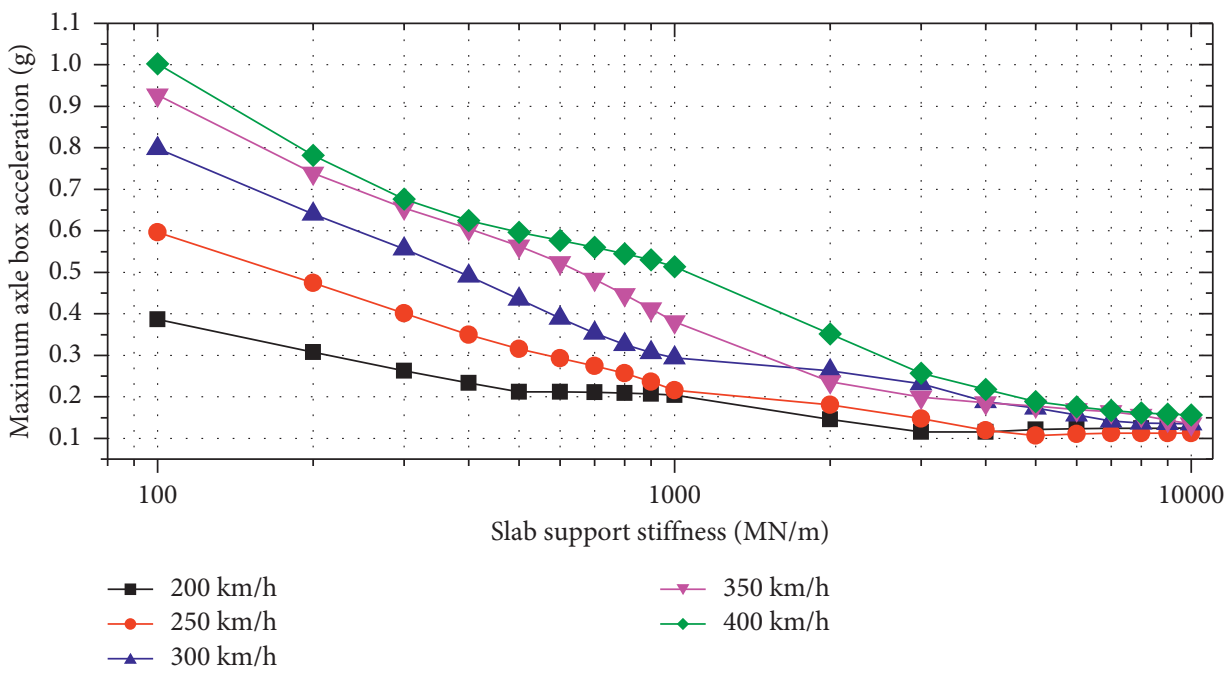

FIGURE 18: Effects of slab support stiffness and vehicle speed on the slab passing-induced axle box acceleration.

of $5.6 \mathrm{~m}$, which is a slab length. As a wheel moves to the connection of slab segments, the normal force shows a decrease and then a rapidly increase as long as the wheel leaves the connection. This procedure generates a highpeak magnitude in the vertical acceleration on the axle box. Furthermore, the lower support stiffness in the CAM yields a large decrease in the wheel/rail normal force and the axle box acceleration. The effects of vehicle speed on the axle box acceleration considering different support stiffnesses of the CAM layer are given in Figure 18. The results show that the maximum axle box acceleration increases with increased vehicle speeds, and the lower support stiffness of CAM layer gives rise to higher axle box accelerations.

\section{Conclusions}

In this study, a coupled vehicle track dynamic model is formulated through coupling a high-speed rail vehicle with slab track via wheels/rails in rolling contact, in which a sliding window method together with the least square criterion is proposed to simulate the train travelling on an infinite long track. The sliding window method is proved to have reasonable accuracy and efficiency through comparing wheel/rail normal forces with those obtained via the existing moving mass model and the moving irregularity model. Then, the experimental results acquired from field tests are used to characterize the steady-state responses induced by the discrete sleeper support and the slab segments. In order 
to identify the main contributors to the steady-state response, the vehicle/track model is employed to investigate the effect of the sleeper supports and the slab segments on wheel/rail normal forces and axle box accelerations considering different parameters in the vehicle and the track system. According to the obtained experimental and numerical results, the conclusions are drawn as follows.

The stiffer rail pad and the higher vehicle speed lead to the larger sleeper passing impact. Especially when the passing frequency approaches the P2 resonance frequency, the sleeper passing-induced responses increase substantially. In winter, the support stiffness of the track system significantly increases due to the extremely low ambient temperature.And the vehicle operating speed falls right in the region where $\mathrm{P} 2$ resonance is excited, which increases the considerable sleeper passing impacts found in the experiments.

The increasing unsprung mass causes the bigger dynamic factor in the wheel/rail force, however, lowers the P2 resonance frequency and the amplitude in the axle box acceleration owing to the larger inertia. The longer sleeper bay yields the higher amplitude in the axle box acceleration and the larger resonance speed, but the corresponding resonance frequency decreases slightly. Although the axle load increase does not change the resonance frequency, the larger axle loads lead to the higher amplitude of the axle box accelerations in the whole speed range. The large vertical damping of the rail pad and primary suspension can reduce the resonance peak.

The slab segment-induced impact can also have significant influences on the wheel/rail normal forces and axle box accelerations. The lower support stiffness of the CAM layer under the slab segments yields higher fluctuations in the wheel/rail normal forces and axle box accelerations. Therefore, it is necessary to maintain the support stiffness of the CAM layer in a controllable condition.

\section{Data Availability}

The data used to support the findings of this study are available from the corresponding author upon request.

\section{Conflicts of Interest}

The authors declare that they have no conflicts of interest.

\section{Acknowledgments}

The present work was supported by the National Key R\&D Program of China (no. 2018YFB1201700), Joint Funds of National Natural Science Foundation of China (no. U1734201), and Opening Project of the State Key Laboratory of Traction Power of Southwest Jiaotong University (no. 2018TPL_T04).

\section{References}

[1] A. Nordborg, "Vertical rail vibrations: parametric excitation," Acta Acustica United with Acustica, vol. 84, pp. 289-300, 1998.
[2] K. Knothe and S. L. Grassie, "Modelling of railway track and vehicle/track interaction at high frequencies," Vehicle System Dynamics, vol. 22, no. 3-4, pp. 209-262, 1993.

[3] D. J. Mead, "Free wave propagation in periodically supported, infinite beams," Journal of Sound and Vibration, vol. 11, no. 2, pp. 181-197, 1970.

[4] L. Jezequel, "Response of periodic systems to a moving load," Journal of Applied Mechanics, vol. 48, no. 3, pp. 613-618, 1981.

[5] C. W. Cai, Y. K. Cheung, and H. C. Chan, "Dynamic response of infinite continuous beams subjected to a moving force-an exact method," Journal of Sound and Vibration, vol. 123, no. 3 , pp. 461-472, 1988.

[6] T. X. Wu and D. J. Thompson, "On the parametric excitation of the wheel/track system," Journal of Sound and Vibration, vol. 278, no. 4-5, pp. 725-747, 2004.

[7] B. Ripke and K. Knothe, "Simulation of high frequency vehicle-track interactions," Vehicle System Dynamics, vol. 24, no. sup1, pp. 72-85, 1995.

[8] R. G. Dong, S. Sankar, and R. V. Dukkipati, “A finite element model of railway track and its application to the wheel flat problem," Proceedings of the Institution of Mechanical Engineers, Part F: Journal of Rail and Rapid Transit, vol. 208, no. 1, pp. 61-72, 1994.

[9] W. M. Zhai, C. B. Cai, and S. Z. Guo, "Coupling model of vertical and lateral vehicle/track interactions," Vehicle System Dynamics, vol. 26, no. 1, pp. 61-79, 1996.

[10] L. Baeza, A. Roda, and J. C. O. Nielsen, "Railway vehicle/track interaction analysis using a modal substructuring approach," Journal of Sound and Vibration, vol. 293, no. 1-2, pp. 112-124, 2006.

[11] X. Xiao, X. Jin, Y. Deng, and Z. Zhou, "Effect of curved track support failure on vehicle derailment," Vehicle System Dynamics, vol. 46, no. 11, pp. 1029-1059, 2008.

[12] L. Ling and X.-s. Jin, "A 3D model for coupling dynamics analysis of high-speed train/track system," Journal of Zhejiang University Science A, vol. 15, pp. 964-983, 2014.

[13] L. Baeza and H. Ouyang, "A railway track dynamics model based on modal substructuring and a cyclic boundary condition," Journal of Sound and Vibration, vol. 330, no. 1, pp. 75-86, 2011.

[14] W. Zhang, Z. Shen, and J. Zeng, "Study on dynamics of coupled systems in high-speed trains," Vehicle System Dynamics, vol. 51, no. 7, pp. 966-1016, 2013.

[15] Y. Q. Sun, M. Dhanasekar, and D. Roach, "A three-dimensional model for the lateral and vertical dynamics of wagontrack systems," Proceedings of the Institution of Mechanical Engineers, Part F: Journal of Rail and Rapid Transit, vol. 217, no. 1, pp. 31-45, 2003.

[16] R. Dong, Vertical Dynamics of Railway Vehicle-Track System, Concordia University, Montreal, Canada, 1994.

[17] X. Wu, W. Cai, M. Chi, L. Wei, H. Shi, and M. Zhu, "Investigation of the effects of sleeper-passing impacts on the high-speed train," Vehicle System Dynamics, vol. 53, no. 12, pp. 1902-1917, 2015.

[18] P. Gullers, L. Andersson, and R. Lundén, "High-frequency vertical wheel-rail contact forces-field measurements and influence of track irregularities," Wear, vol. 265, no. 9-10, pp. 1472-1478, 2008.

[19] Z. G. Li and T. X. Wu, "On vehicle/track impact at connection between a floating slab and ballasted track and floating slab track's effectiveness of force isolation," Vehicle System Dynamics, vol. 47, no. 5, pp. 513-531, 2009.

[20] M. F. M. Hussein and H. E. M. Hunt, "Modelling of floatingslab track with discontinuous slab," Journal of Low Frequency 
Noise, Vibration and Active Control, vol. 25, no. 2, pp. 111118, 2006.

[21] J. Färm, "Interior structure-borne sound caused by the sleeper-passing frequency," Journal of Sound and Vibration, vol. 231, no. 3, pp. 831-837, 2000.

[22] T. X. Wu and D. J. Thompson, "On the rolling noise generation due to wheel/track parametric excitation," Journal of Sound and Vibration, vol. 293, no. 3-5, pp. 566-574, 2006.

[23] T. X. Wu, "Parametric excitation of wheel/track system and its effects on rail corrugation," Wear, vol. 265, no. 9-10, pp. 1176-1182, 2008.

[24] T. Szolc, "Medium frequency dynamic investigation of the railway wheelset-track system using a discrete-continuous model," Archive of Applied Mechanics (Ingenieur Archiv), vol. 68 , no. 1, pp. 30-45, 1998.

[25] X. Jin, X. Xiao, Z. Wen, and Z. Zhou, "Effect of sleeper pitch on rail corrugation at a tangent track in vehicle hunting," Wear, vol. 265, no. 9-10, pp. 1163-1175, 2008.

[26] J. J. Kalker, "A fast algorithm for the simplified theory of rolling contact," Vehicle System Dynamics, vol. 11, no. 1, pp. 1-13, 1982.

[27] H. Hertz, "On the contact of elastic solids," Journal für die reine und angewandte Mathematik, vol. 92, pp. 156-171, 1880.

[28] W. Cai, M. Chi, G. Tao, X. Wu, and Z. Wen, "Experimental and numerical investigation into formation of metro wheel polygonalization," Shock and Vibration, vol. 2019, Article ID 1538273, p. 18, 2019.

[29] S. Song, W. Zhang, P. Han, and D. Zou, "Sliding window method for vehicles moving on a long track," Vehicle System Dynamics, vol. 56, no. 1, pp. 113-127, 2017.

[30] Å. Björck, Numerical Methods for Least Squares Problems, SIAM, Philadelphia, PA, USA, 1996.

[31] H. H. Jenkins, J. E. Stephenson, G. A. Clayton, G. W. Morland, and D. Lyon, "The effect of track and vehicle parameters on wheel/rail vertical dynamic loads," Railway Engineering Journal, vol. 3, pp. 2-16, 1974.

[32] K. Wei, F. Wang, P. Wang, X. Liu, and P. Zhang, "Effect of temperature and frequency dependent dynamic properties of rail pads on high speed vehicle track coupled vibrations," Vehicle System Dynamics, vol. 55, no. 3, pp. 351-370, 2017.

[33] J. C. O. Nielsen, R. Lundén, A. Johansson, and T. Vernersson, "Train-track interaction and mechanisms of irregular wear on wheel and rail surfaces," Vehicle System Dynamics, vol. 40, no. $1-3$, pp. 3-54, 2003.

[34] A. Johansson and J. C. O. Nielsen, "Rail corrugation growthinfluence of powered wheelsets with wheel tread irregularities," Wear, vol. 262, no. 11-12, pp. 1296-1307, 2007.

[35] S. L. Grassie, "Rail corrugation: characteristics, causes, and treatments," Proceedings of the Institution of Mechanical Engineers, Part F: Journal of Rail and Rapid Transit, vol. 223, no. 6, pp. 581-596, 2009.

[36] P. T. Torstensson, J. C. O. Nielsen, and L. Baeza, "Dynamic train-track interaction at high vehicle speeds-modelling of wheelset dynamics and wheel rotation," Journal of Sound and Vibration, vol. 330, no. 22, pp. 5309-5321, 2011.

[37] L. Baeza, P. Vila, G. Xie, and S. D. Iwnicki, "Prediction of rail corrugation using a rotating flexible wheelset coupled with a flexible track model and a non-Hertzian/non-steady contact model," Journal of Sound and Vibration, vol. 330, no. 18-19, pp. 4493-4507, 2011.

[38] X. Wu, M. Chi, and P. Wu, "Influence of polygonal wear of railway wheels on the wheel set axle stress," Vehicle System Dynamics, vol. 53, no. 11, pp. 1535-1554, 2015.
[39] G. Tao, L. Wang, Z. Wen, Q. Guan, and X. Jin, "Measurement and assessment of out-of-round electric locomotive wheels," Proceedings of the Institution of Mechanical Engineers, Part F: Journal of Rail and Rapid Transit, vol. 232, no. 1, pp. 275-287, 2018. 